Florida International University FIU Digital Commons

4-5-1999

\title{
Age-related differences in self-reported health and functional abilities in the elderly
}

Cynthia Garner Condon

Florida International University

DOI: $10.25148 /$ etd.FI14060889

Follow this and additional works at: https://digitalcommons.fiu.edu/etd

Part of the Occupational Therapy Commons

\section{Recommended Citation}

Condon, Cynthia Garner, "Age-related differences in self-reported health and functional abilities in the elderly" (1999). FIU Electronic Theses and Dissertations. 2419.

https://digitalcommons.fiu.edu/etd/2419

This work is brought to you for free and open access by the University Graduate School at FIU Digital Commons. It has been accepted for inclusion in FIU Electronic Theses and Dissertations by an authorized administrator of FIU Digital Commons. For more information, please contact dcc@fiu.edu. 
FLORIDA INTERNATIONAL UNIVERSITY

Miami, Florida

AGE-RELATED DIFFERENCES

IN SELF-REPORTED HEALTH AND

FUNCTIONAL ABILITIES IN THE ELDERLY

A thesis submitted in partial fulfillment of the

requirements for the degree of

MASTER OF SCIENCE

in

OCCUPATIONAL THERAPY

by

Cynthia Garner Condon 
To: Dean DeLois P. Weekes

College of Health Sciences

This thesis, written by Cynthia Garner Condon, and entitled Age-related Differences in Self-Reported Health and Functional Abilities in the Elderly, having been approved in respect to style and intellectual content, is referred to you for judgment.

We have read this thesis and recommend that it be approved.

Pamela Shaffner

Paulette Johnson

Gail Ann Hills, Major Professor

Date of Defense: April 5, 1999

The thesis of Cynthia Garner Condon is approved.

Dean DeLois P. Weekes

College of Health Sciences

Dean Richard L. Campbell

Division of Graduate Studies

Florida International University, 1999 


\section{ACKNOWLEGDMENTS}

I wish to thank the members of my committee for their guidance with this endeavor. I would especially like to thank my major professor, Dr. Gail Ann Hills, for allowing me the opportunity to use her research material for my thesis. I am also grateful to Dr. Hills for providing appreciated advice and support throughout my studies.

I thank Dr. Paulette Johnson for her guidance regarding the analysis and interpretation of the data. I also thank Professor Shaffner for her insightful comments.

Finally, my husband, Keith Condon, deserves a special thanks. His encouragement and enduring support have made it possible for me to pursue my graduate studies. 


\author{
ABSTRACT OF THE THESIS \\ AGE-RELATED DIFFERENCES IN SELF-REPORTED HEALTH AND \\ FUNCTIONAL ABILITIES IN THE ELDERLY \\ by \\ Cynthia Garner Condon \\ Florida International University, 1999 \\ Miami, Florida \\ Professor Gail Ann Hills, Major Professor
}

The purpose of this study was to compare age-related differences in selfreported health and self-reported functional abilities from 1971 individuals surveyed in the Comprehensive Needs Assessment Survey of Elders 60 years and Older in Dade County. The responses were divided into four age groups: (a) 60 to 64 years, (b) 65 to 74 years, (c) 75 to 84 years, and (d) 85 years and older and results compared.

The study found that self-reported health ratings were significantly different across the four age groups and exhibited a gradual decrease in favorable health ratings with age. For all ages, at least $60 \%$ of the respondents rated their health as either "excellent" or "good", but this percentage decreased from $68.1 \%$ in the youngest group to $60.7 \%$ in the oldest.

The study also found significant differences across age groups in functional abilities as measured by reported difficulties with eight activities of 
daily living (ADLs) and eight instrumental activities of daily living (IADLs). For all ADLs and IADLs, the percentage of respondents reporting difficulty increased with age, but this increase was most dramatic in the oldest age group (85+ years).

There was a positive relationship between self-reported health and functional ability in the four age groups and as the number of difficulties with ADLs or IADLs increased, self-reported health became poorer. However, the relationship between self-reported health and functional ability tended to weaken with age. Pearson correlation coefficients between self-reported health and difficulties with ADLs decreased from the youngest age group $(r=.463)$ to the oldest group $(r=.310)$. Similarly, the correlation between self-reported health and difficulties with IADLs was higher in the two younger age groups $(r=.326$ and $\underline{r}=.420)$ than the two older groups $(\underline{r}=.249$ and $\underline{r}=.215)$. Pairwise $\mathrm{z}$-tests revealed that the correlations of the oldest age group were significantly different from the other age groups.

The study also found gender differences across age groups.

The findings from this study suggest that there is a relationship between self-reported health and functional abilities and this relationship tends to weaken with age. The implications of these findings for occupational therapy with elderly clients are discussed. 


\section{TABLE OF CONTENTS}

CHAPTER

PAGE

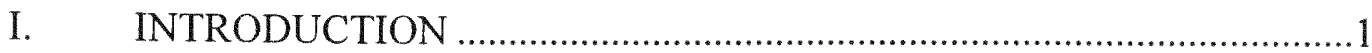

Statement of Problem and Significance of the Study ..................................4

Theoretical Perspective for this Study ....................................................5

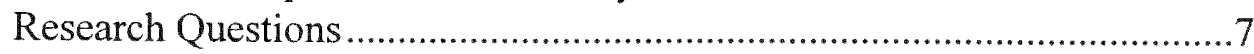

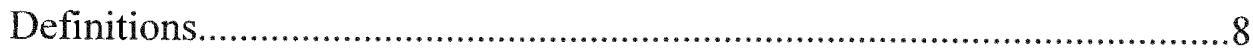

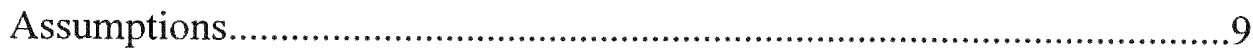

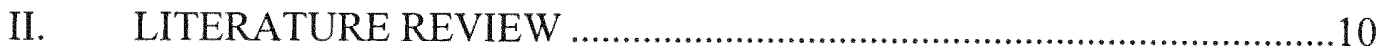

Characteristics of the Elderly in the United States ...................................10

Functional Abilities of the Elderly ...........................................................14

Assessment of Functional Abilities in Elderly Populations........................15

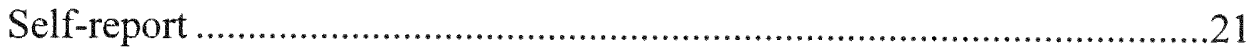

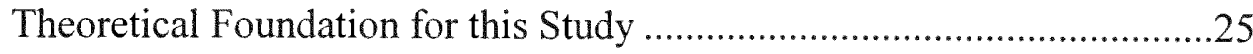

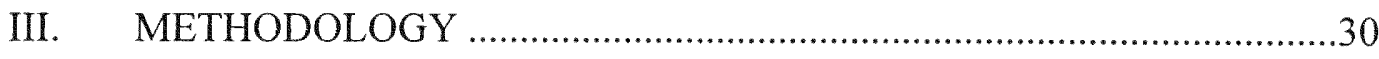

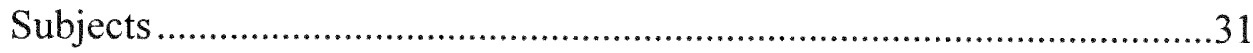

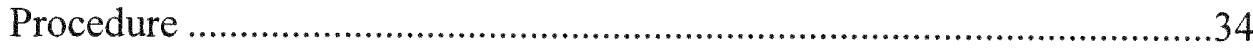

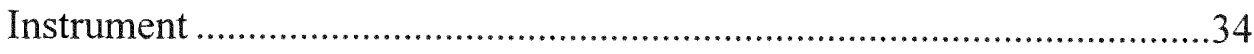

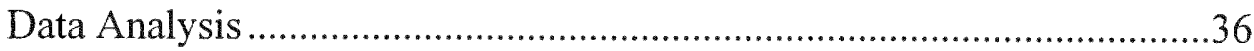

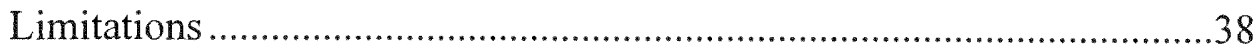

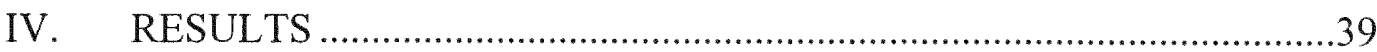

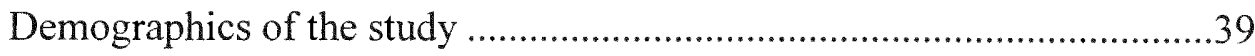

Demographics of the four age groups ........................................................40

Research question one: Is there a relationship between

self-reported health and age of the elderly? ...............................................46

Research question two: Is there a relationship between

self-reported functional ability and age of the elderly? .............................50

Research questions three and four: Is there a relationship between self-reported health and self-reported functional ability of the elderly? and Does the relationship between self-reported health and self-reported functional ability differ among four age groups of elderly individuals? ...80

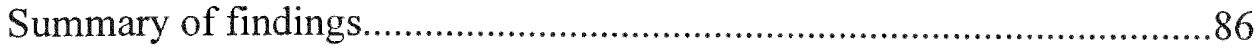

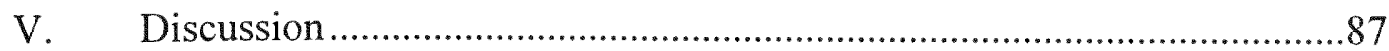

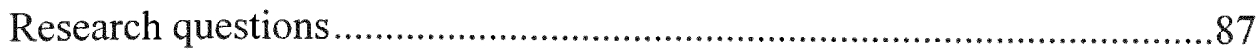

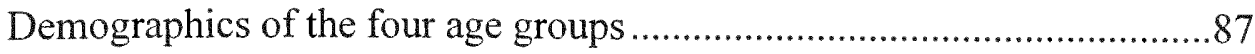


Research question one: Is there a relationship between

self-reported health and age of the elderly?

Research question two: Is there a relationship between

self-reported functional ability and age of the elderly?

Research questions three and four: Is there a relationship

between self-reported health and self-reported functional ability

of the elderly? and Does the relationship between self-reported

health and self-reported functional ability differ among four age

groups of elderly individuals?

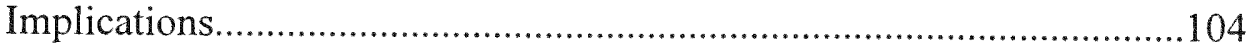

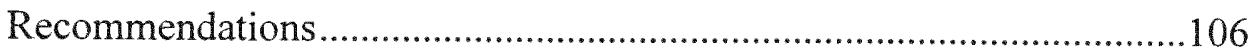

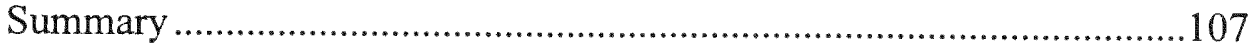

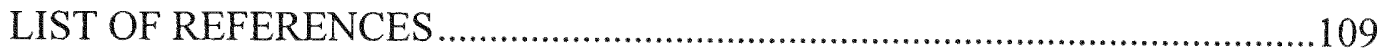




\section{LIST OF TABLES}

TABLE

PAGE

1. Age Distribution of Study Sample

2. Gender Distribution by Age Group

3. Ethnic Distribution by Age Group

4. Distribution of Highest Level of Education by Age Group.

5. Distribution of Annual Income by Age Group .45

6. Distribution of Self-Reported Health by Age Group.

7. Distribution of Self-Reported Health by Age Group and Gender .49

8. Presence of Difficulties with ADLs by Age Group .53

9. Presence of Difficulties with ADLs by Age Group among Females

10. Presence of Difficulties with ADLs by Age Group among Males

11. Presence of Difficulties with IADLs by Age Group ................................59

12. Presence of Difficulties with IADLs by Age Group among Females

13. Presence of Difficulties with IADLs by Age Group among Males

14. Level of Difficulties with ADLs by Age Group .64

15. Level of Difficulties with IADLs by Age Group ....................................68

16. Number of Difficulties with ADLs by Age Group ..................................70

17. Number of Difficulties with ADLs by Age Group and Gender.................72

18. Number of Difficulties with IADLs by Age Group ................................. 74 
19. Number of Difficulties with IADLs by Age Groups and Gender..............75

20. Mean Number of Difficulties with ADLs by Age Group ….....................77

21. Mean Number of Difficulties with IADLs by Age Group .......................79

22. Correlations between Self-Reported Health and Mean Number of Difficulties with ADLs by Age Group

23. Correlations between Self-Reported Health and Mean Number of Difficulties with IADLs by Age Group 


\section{CHAPTER I}

Introduction

Within the United States (US), as well as in other industrialized nations of the world, the proportion of elderly individuals in the population has been steadily increasing. Among gerontologists, the term, "elderly", has been traditionally used in reference to people over the age of 60 or 65 years, the age at which most workers in the US retire from full-time employment (Biggar, 1985). During the 20th century, the elderly population in the US has grown more than ten-fold from 3.1 million ( $4 \%$ of the population) in 1900 to 31.1 million ( $12.5 \%$ of the population) in 1990 (US Bureau of the Census, 1996). By the year 2030, the US Bureau of the Census predicts that the proportion of the population over the age of 65 years will be greater than $20 \%$. In fact, one of the most rapidly growing segments of society is the "oldest-old" (people aged 85 years and older). Approximately three million people (1.3\% of the population) constitute the oldestold living in the US today and this number is expected to increase into the next century. The dramatic increase in the number of older people has been primarily due to an increase in life expectancy. In the US, life expectancy at birth has risen from 47 years in 1900 to 75.5 years in 1990 (US Bureau of the Census, 1996). Current demographic trends, coupled with medical advances that have greatly reduced the risk of life-threatening illnesses, have enhanced the likelihood that the elderly will continue to represent a significant segment of the population (US Bureau of the Census, 1996). 
Self-assessments of health and functional abilities are tools commonly used in the development of treatment plans for the elderly. In the past, it was assumed that self-evaluations of health status reflected functional status, such that declines in function would be accompanied by similar declines in self-reported health. However, in recent years, more extensive investigations using large samples of elderly populations have reached intriguing and often contradictory conclusions regarding the influence of functional abilities on subjective health status in older adults.

The relationship between self-reported health and functional ability in the elderly is not as apparent as once believed, and recent studies suggest that this relationship may be modified with age. In other words, the correlation between self-reported health status and functional abilities may differ in different age groups of elderly adults. To date, conclusions reached concerning the age-related differences in health perceptions and functional abilities have been inconclusive. For instance, in comparisons of self-reported health and functional status in different age groups of elderly, some researchers have concluded that as functional status declines, self-assessments of health also decline (Mossey et al., 1982; Murray et al., 1982). Considering different studies other researchers have concluded that regardless of functional status self-reported health tends to remain relatively stable throughout old age, with most elderly adults reporting relatively good health (Ailinger, 1989; Christenson et al., 1994; Rodin and McAvay, 1992). These researchers have noted that despite the fact that the oldest-old ( $85+$ years) 
and old-old (75-84 years ) tend to experience more physiological problems and physical limitations than the young-old (65-74 years), their perceptions regarding their health status are not necessarily lower. Still others have found that, in comparisons of elderly individuals with similar functional limitations, older respondents tend to report better health than younger ones (Idler, 1993; Johnson and Wolinksy, 1993).

Researchers have also noted that among the elderly, positive perceptions of health are linked to lower risks of mortality and higher levels of life satisfaction (Idler and Benyamini, 1997). Some researchers have concluded that older adults may not regard the presence of functional limitations as necessarily affecting their quality of life if they are able to adapt to these changes (Bernard et al., 1997; Femia et al., 1997; Langlois et al., 1996). In a longitudinal study of individuals over the age of 85 years, Femia et al. (1997) found that subjects, who maintained positive outlooks about their health, despite outward physical limitations, were able to maintain functional independence longer than those who had less positive outlooks on personal health.

Researchers as well as some practitioners in health related fields are beginning to appreciate the role that self-perceptions play in the maintenance of health. Consequently, it is essential that these perceptions are properly interpreted. In the past, attitudes and perceptions of elderly patients, especially with concerning feelings of ill-health, have been largely ignored as being inevitable consequences of aging and loss of functional abilities. Research now 
suggests that rather than ignoring an older person's self-report of poor health as being an obvious sign of aging, it may be important to address it as an important warning sign of a change in health status. The elder's perception of poor health may have been heretofore undetected but may be remediated with treatment. Likewise, an elderly individual's report of "being in good health" may imply that that individual is successfully adapting to changes in functional status. However, just because an elderly individual reports good health, does not necessarily mean that the person would not benefit from interventions that address the functional limitations and ameliorate, or even postpone, the prospect of future functional decline.

Statement of Problem and Significance of the Study

Recent studies on perceptions of the elderly have proposed new hypotheses about the relationships between self-perceptions and the maintenance of functional ability. More studies on representative samples of elderly populations are necessary to fully explain these relationships in order to use the knowledge effectively in a clinical setting. Dade County, Florida has a large population of elderly individuals from a broad age spectrum, with inhabitants ranging in age from 60 years old to over 85 years. The data collected from the Comprehensive Needs Assessment Survey of Elders 60 years and older in Dade County contained the necessary information to answer questions about the relationships between self-reported health and function. 
The purpose of this study was to compare age-related differences in selfreported health and functional abilities in four age groups of elderly individuals from Dade County, Florida.

\section{Theoretical Perspective for this Study}

In this study, two theoretical frameworks, the Disablement Process and the Model of Human Occupation (MOHO), were used to explain the nature of functional performance in the elderly and the relationship of psychological processes to functional performance. The Disablement Process explained the difference between functional impairments, limitations and disability and demonstrated how, especially in the elderly, the development of disabilities is a gradual process which takes place over an extended period of time and is influenced by both internal and external factors (Verbrugge and Jette, 1994). MOHO was used to examine the relationship between functional performance and internal belief systems in the elderly.

The Disablement Process. The Disablement Process is a model developed by Verbrugge and Jette (1994) which explains the consequences of disease processes on functional abilities. According to this model, the primary pathway for the development of disability occurs along a continuum in successive stages:

(a) pathology, (b) impairment, (c) functional limitation, and (d) disability. Pathology leads to impairments, which in turn produce functional limitations, and functional limitations eventually lead to the development of a disability. Functional limitation is defined as the level of difficulty a person has in 
performing physical or mental actions which produce tasks. In contrast, disability is defined in terms the level of difficulty a person has in the performance of purposeful tasks independently within the context of the person's environment. For example, difficulty in walking is considered a functional limitation and the inability to perform light housework is considered a disability.

Model of Human Occupation. The Model of Human Occupation (MOHO) can be used as a framework to examine the relationships between self-reported health and functional abilities of different age groups of elderly (Kielhofner, 1995; Kielhofner and Forsyth, 1997). According to MOHO, human beings are viewed as dynamic open systems that produce and are affected by occupational behavior (purposeful activity). A change or disruption in any aspect of the system can lead to a change in performance. Furthermore, a person's volition or personal causation can have profound influences on his or her ability to perform purposeful activities. The relationship between volition and performance may be especially important in the elderly who are challenged by increasing physical limitations caused by physiological changes associated with the normal aging process, as well as limitations associated with chronic health conditions. In order to successfully adapt to these limitations caused by diminishing physical capacities, it may be necessary to alter one's volitional system, which includes altering how one measures his or her own health status.

In applications of occupational therapy with the elderly, the development of successful intervention strategies relies on an accurate understanding of the 
perceptions and priorities of the client. Occupational therapy stresses the importance of understanding the influences that psychological, environmental and biological factors have on individual performance and quality of life. In working with the elderly it is particularly important to understand that these influences are dynamic processes and the influence of each on a person's health and well-being may continue to change as the person ages.

\section{$\underline{\text { Research Questions }}$}

This study compared the relationship between self-reported health perceptions and functional abilities in four age groups (60 to 64 years old, 65 to 74 years old, 75 to 84 years old, 85 years old and over) of elderly individuals in Dade County, Florida.

The following research questions were investigated:

(1) Is there a relationship between self-reported health and age of the elderly?

(2) Is there a relationship between self-reported functional ability and age of the elderly?

(3) Is there a relationship between self-reported health and self-reported functional ability of the elderly?

(4) Does the relationship between self-reported health and self-reported functional ability differ among four age groups of elderly individuals? 


\section{Definitions}

Elderly: Individuals 60 years of age and older.

Youngest-old: Individuals 60 to 64 years of age.

Young-old: Individuals 65 to 74 years of age.

Old-old: Individuals 75 to 84 years of age.

Oldest-old: Individuals 85 years of age and older.

Self-reported health status: An overall health rating of excellent, good, fair or poor in comparison to others of your age.

ADLs: Activities of daily living including bathing, dressing, eating, toileting, taking care of appearance, transferring, getting up and down stairs, and walking.

IADLs: Instrumental activities of daily living including taking medications, preparing meals, shopping, managing money, using the telephone, doing laundry, doing other housework, and getting to places in the community. Functional ability: Level of difficulty reported in the performance of ADLs and IADLs including no difficulty, some difficulty, a lot of difficulty, and completely unable to perform an activity without personal assistance or special equipment. 


\section{Assumptions}

Assumptions of this study were: (a) the sample surveyed for the Dade County Needs Assessment Survey was representative of the elderly population in Dade County, (b) the survey instrument contained the appropriate data to answer the research questions, (c) the subjects interviewed for the survey understood the questions and responded appropriately, (d) the interviewers recorded the responses accurately, (e) and the subjects answered the questions truthfully. 


\section{CHAPTER II}

\section{LITERATURE REVIEW}

\section{Characteristics of the Elderly in the United States}

Demographics of the elderly population. During the twentieth century, in the United States (US), as well as in other industrialized nations of the world, the proportion of elderly individuals in the population has been steadily increasing. Among gerontologists, the term, "elderly", has been traditionally used in reference to people over the age of 60 or 65 years, the age at which most workers in the US retire from full-time employment (Biggar, 1985). According to the US Bureau of the Census (1996), the growth rate in the elderly population has far exceeded that in the entire population. During the twentieth century, the elderly population in the US has grown more than ten-fold from 3.1 million ( $4 \%$ of the population) in 1900 to 31.1 million (12.5\% of the population) in 1990 (US Bureau of the Census, 1996). In comparison, the entire population has only tripled in size during the same period. In 1994, the median age in the US was 34 years old. By the year 2030, the US Bureau of the Census predicts that the median age will be over 39 years old with more than $20 \%$ of the population over the age of 65 years. In fact, the most rapidly growing segment of society is the "oldest-old" (people aged 85 years and older). Approximately three million people $(1.3 \%$ of the population) constitutes the oldest-old living in the US today and this number is expected to increase into the next century. The dramatic increase in the number of older people has been primarily due to an increase in life expectancy, resulting 
from advances in health and medical practices. In the US, life expectancy at birth has risen from 47 years in 1900 to 75.5 years in 1990 (US Bureau of the Census, 1996). It is important to note, however, that there remains a disparity in life expectancies of males and females as well as among the major ethnic groups living in the US. For instance, according to figures from the 1990 US Census, the life expectancy at birth for women is 79 years as compared to 72 years for men. Similarly, the average life expectancy at birth for Caucasians (76 years) continues to be significantly higher than that of African Americans and other ethnic groups (69 years). Even though gender and ethnic demographic profiles reflected in the elderly population are dissimilar, the overall current trend towards increased longevity enhances the likelihood the elderly will continue to represent a significant segment of the population (US Bureau of the Census, 1996).

Chronic health conditions. Medical advances of the 20th century have greatly reduced the risk of life-threatening illnesses and contributed to the increased probability of surviving into old age. Chronic health problems, including arthritis, ischemic heart disease, diabetes, hypertension, hearing impairments, chronic back conditions, varicose veins, visual impairments and atherosclerosis, are prevalent in older adults and the incidence of co-morbidity of several chronic conditions substantially increases with age (Verbrugge and Jette, 1994). On average, women tend to have higher numbers of multiple conditions, but men tend to experience higher rates of ischemic heart disease, diabetes and atherosclerosis. However, after the age of 75 years the prevalence of 
atherosclerosis increases among women. Unfortunately, no effective treatments have been discovered for chronic health conditions, and they often lead to the development of disabling side-effects (Verbrugge and Jette, 1994). As the average life-span continues to increase, the potential for maintaining a healthy and independent life in the advanced age groups becomes increasingly problematic (Biggar, 1985).

In comparison to the recent past, people today are delaying the effects of chronic health conditions and are remaining healthier for a longer portion of their lives. Nevertheless, the risk of living for a significant period of time with agerelated functional limitations or disabilities still exists. Using longitudinal data from the National Long Term Care Surveys compiled in 1982, 1984 and 1989, Manton, Corder and Stallard (1993) report that the trend nationwide appears to be directed towards a decline in the proportion of elderly with functional limitations, but because of the continued population growth in the older age groups, the absolute number of elderly individuals with disabilities probably will not decrease for many decades. They predict that in the US there will continue to be significant numbers of older persons with functional disabilities who will require assistance in everyday living.

Major age classifications of the elderly. In studies that explore relationships and trends in the elderly, research methodologies are constantly evolving to reflect the continually changing composition of the elderly population. For example, in early studies, individuals aged 75 years and older were usually 
clustered into the oldest age group. For purposes of statistical analyses, most populations contained insufficient numbers of individuals over the age of 75 years to be divided into additional age categories (Bowling et al., 1993). In recent years, the proportion of older adults has increased sufficiently to allow the oldest age category to be modified to include only those individuals 85 years of age and older.

Most researchers now recognize at least three or four major age categories in elderly populations and these are: the youngest-old or late adulthood (50 to 64 years), the young-old ( 65 to 74 years), the old-old ( 75 to 84 years), and the oldestold (over 85 years). These categories correspond roughly to trends in physiological functioning that occur as part of the normal aging process and that may have a direct impact on functional abilities and self-perceptions in aging adults (Biggar, 1985). For example, during late adulthood, degenerative diseases normally begin to appear, but do not interfere with independent functioning and self-maintenance. During the young-old stage, health problems become chronic and begin to have detrimental effects, but independent functioning is usually still possible. Among the old-old, health problems have reached a sufficient level of severity and number to precipitate the development of functional limitations. Among the oldest-old, the impact of functional limitations and disability becomes the most severe and maintenance of an independent life-style is clearly threatened. 


\section{Functional Abilities of the Elderly}

Surveys of community-dwelling elderly adults have revealed two important trends with regards to the functional abilities of older adults. The two trends which have emerged are: (a) the majority of adults over the age of 60 years do not report having significant functional limitations or disabilities, and (b) functional abilities tend to dramatically decline with increasing age among the elderly (Maddox et al., 1994; Manton et al., 1993; Markides and Lee 1990).

In a comparison of the average levels of ADL difficulties reported from 11 national surveys conducted between 1982 and 1987, Wiener et al. (1990) found the proportion of elderly adults reporting difficulties with at least one ADL ranged from $5 \%$ to $8.1 \%$.

Because elderly adults report higher levels of difficulty with IADLs than with ADLs, in studies that use both IADLs and ADLs to determine disability rates, the incidence of functional limitations and disabilities is higher than in those which consider ADLs alone. However, the rate of disability remains relatively low (Spector and Fleishman, 1998). For example, in a study based on data from the 1989 National Long Term Care Survey of adults over the age of 65 years, Manton et al. (1993) found that $22.6 \%$ of the respondents reported a chronic disability with at least one ADL or IADL. In their study, a chronic disability was defined as the inability to perform an ADL without personal or mechanical assistance or the inability to perform an IADL because of a health problem (Manton et al., 1993). 
According to most national surveys, the most frequently reported disabilities in IADLs are difficulties with getting outside and doing housework (US Bureau of the Census, 1996). Among the ADLs, difficulties in walking and bathing are usually most frequently reported and difficulty with eating, the least reported (US Bureau of the Census, 1996).

Survey data are relatively consistent in reporting rather dramatic differences in the prevalence of functional limitations and disabilities in different age groups of the elderly. For example, the young-old tend to report relatively low rates of limitations, whereas the old-old report very high rates. According to the 1989 National Long Term Care Survey, the prevalence of chronic disabilities increased with age from $4.8 \%$ in ages 65 to 74 years, to $9.5 \%$ in ages 75 to 84 years, to $23.4 \%$ in ages 85 years and older (Manton et al., 1993).

Gender differences in the prevalence of functional limitations and disabilities have also been noted. According to the 1991 Survey of Income and Program Participation conducted by the US Census Bureau, more elderly women reported having difficulties in performing ADLs and IADLs due to health problems than men (US Bureau of the Census, 1996). Women also tended to report more lower body limitations, such as walking, climbing stairs, than men (Stump et al., 1997).

\section{Assessment of Functional Abilities in Elderly Populations}

Surveys of the Elderly. In community-dwelling elderly populations, the self-report survey is a common method for data collection on issues relating to 
health and functional status. In recent years self-report questionnaires have proven to be a cost-effective and relatively simple means of collecting large amounts of data from large samples of the elderly (Cousins, 1997).

Many of these surveys have been need assessment studies which have been used to identify the needs unique to the elderly. These need surveys have served as guides for the formulation of public policy, especially with regards to issues of long-term health care and allocation of public funds (Weiner et al., 1990). Collecting information on needs and attitudes of the elderly is especially valuable, because, in general, older adults tend to need and utilize a greater proportion of health-care related services than younger individuals. The dramatic increase in the elderly population has created greater demands for these services.

Surveys of elderly populations have provided data for both cross-sectional as well as longitudinal studies. Among national surveys in the US that are also components of larger longitudinal studies are the National Long Term Care Survey, initiated in 1982 and the Longitudinal Study on Aging, initiated in 1984 (Weiner et al. 1990). More recently, national surveys have targeted specific segments of the elderly population with special needs. Included among these is the Asset and Health Dynamics Among the Oldest Old survey, which was initiated in 1993 and sampled community-dwelling adults over 70 years of age (Stump et al., 1997). The Women's Health and Aging Study was conducted from 1992 to 1995 and surveyed community-dwelling women over the age of 65 years with disabilities (Fried et al., 1995). Regional needs assessment surveys of 
elderly populations are also periodically conducted in many parts of the country that have large proportions of elderly inhabitants, such as Dade County, Florida. Other recent surveys include the Younker Gerontology Project in Iowa, the Los Angeles County Area Agency on Aging survey in California and the Fairfax Area Agency on Aging in Virginia (Reviere et al., 1994). Large-scale national surveys of the elderly have also been conducted in other industrialized nations of the world, including Canada (Mossey and Shapiro, 1982), Hong Kong (Ho et al., 1997), Sweden (Femia et al., 1997), Australia (McCallum et al., 1994), Germany (Baltes and Smith, 1997), Denmark (Schroll et al., 1997), England (Bowling and Grundy, 1997), and the Netherlands (Hoeymans et al., 1997).

One significant finding from many of these surveys concerns the role that functional status plays in predicting independence of the elderly at home and in the community. Declines in functional status have been associated with increased need for both formal and informal assistance (Norgard and Rodgers, 1997). For example, functional status has been found to be a useful predictor of the use of health care services, admission to nursing homes and hospitals, the use of formal or informal in-home caregivers, changes in living arrangements, and the risk of mortality (Chappell, 1994; Norgard and Rodgers, 1997; Wiener et al., 1990; Zarit et al. 1995).

Nature of survey questions. Most health surveys include questions about self-reported health and are used by researchers to describe an important aspect of health in large populations (Manderbacka and Lundberg, 1996). In surveys of 
elderly populations, most questions about self-reported health ask respondents to compare their health to others their own age or to the general population and they are asked to rate their health on a Likert-type scale (Idler and Benyamini, 1997). According to Idler and Benyamini (1997), questions about self-reported health also serve as a conversational way for the interviewer to broach the topic of personal health and ask more in-depth and intimate questions regarding functional status.

Questions about ADLs and IADLs often vary in surveys in terms of the wording of the questions and the specific activities covered. For example, many researchers use different criteria to operationally define functional limitation. In a comparison of ADL questions from national surveys, Wiener et al. (1990) discovered differences in methodologies related to the types of activities addressed, the criteria for rating levels of difficulty, the reporting of assistive devices, and the duration of the limitation. In a similar study, Jette (1994) concluded that within a single survey instrument, estimates of functional limitations varied depending on what questions were used to measure limitation. He found that using questions about the levels of difficulty with a task produced higher overall estimates of functional limitations than using questions about the amount of assistance required for the performance of a task.

Despite inconsistencies in survey questionnaires, there are several common activities of daily life that are addressed in most surveys. ADLs usually covered include questions concerning eating, toileting, transferring, dressing and 
bathing (Wiener et al., 1990). IADLs usually addressed are questions about preparing meals, doing housework, handling money, shopping and getting out of the house (Rodgers and Miller, 1997).

Hierarchical nature of ADLs and IADLs. In addition to the controversy over wording of questionnaires, there is also a difference of opinion regarding the most worthwhile way to draw conclusions about functional abilities and limitations from the questions about ADLs and IADLs. Some researchers treat IADLs and ADLs as separate constructs, while others group ADLs and IADLs into categories by physical, cognitive, or social requirements of the tasks. Most researchers agree that ADLs and IADLs present varying degrees of challenges. The general assumption is that IADLs are more complex tasks than ADLs and survey data supports this inference in that the frequencies of responses about ADLs and IADLs from most survey results can generally be arranged hierarchically in order of increasing levels of difficulty (Fisher, 1992). On average, older adults generally report higher levels of difficulty with IADLs than with ADLs (Femia et al., 1997; Spector et al., 1987).

Despite the fact that there appears to be a hierarchical relationship of ADLs and IADLs, researchers have failed to agree on the exact ranking of these activities and many researchers prefer to present data from ADLs and IADLs separately as representing two different dimensions of functioning (Spector and Fleishman, 1998). For example, some investigators calculate one disability index for ADLs and another for IADLs. However, others have noted that in some 
survey data there is a certain degree of overlap between the reported levels of difficulty in ADLs and IADLs and they question the utility of separating out ADLs and IADLs (Spector and Fleishman, 1998). For example, in an attempt to rank-order the reported levels of difficulties in 15 ADLs and IADLs from the 1989 National Long Term Care Survey, Spector and Fleishman (1998) found that, for the most part, the number of individuals reporting difficulties was greater for IADLs than for ADLs. However, one ADL, "bathing", fell within the range of the IADLs and one IADL, "telephoning", fell within that of the ADLs. Spector and Fleishman (1998) report that computer modeling of their data which addressed the dimensionality of ADLs and IADLs supports their recommendation of reporting difficulties with ADLs and IADLs as a single measure of disability. However, others disagree with the concept of combining ADLs and IADLs into one measure of functioning and point out the fact that one of the primary variables which affects functioning in the elderly is cognition (Femia et al., 1997; Johnson and Wolinsky, 1993; 1994; Stump et al., 1997; Zarit et al., 1993, 1995). Based on their analysis of data from the Longitudinal Study on Aging, Johnson and Wolinsky $(1993 ; 1994)$ concluded that the physical and cognitive components of functional limitations were best characterized by grouping ADLs and IADLs into three broad categories. In order of complexity, the three categories they suggested were basic ADLs, household ADLs and advanced ADLs. Basic ADLs consisted of the traditional ADL activities of bathing, dressing, transferring and toileting. Household ADLs were composed of 
several traditional IADL activities including shopping, meal preparation and housework. Advanced ADLs were the most complex activities and represent both traditional ADLs and IADLs, including eating, managing money and using the telephone. In their scheme, mobility activities, such as walking, standing, and using stairs, were used to measure lower body limitations and were not considered as part of the ADLs or IADLs.

Others have also noted that cognitive level plays an extremely important role in the evaluation of performance in the oldest old. In a survey of functional limitations in a sample of individuals over the age of 84 years in Sweden, Zarit and co-workers (Zarit et al. 1993, 1995; Femia, Zarit and Johansson, 1997) reported that most of the individuals who had demonstrable cognitive impairments also exhibited significant $\mathrm{ADL}$ and IADL limitations.

\section{$\underline{\text { Self-report }}$}

Validity of Self-Report. In the past, researchers have questioned the validity of self-reports based on the possible subjective nature of such reports, but more recent studies have shown that self-report instruments are a valid method of data collection (Cress et al., 1995; Jacobs et al., 1992; Myers et al., 1993; Siu et al., 1993). Some researchers have viewed measures of functional ability, such as physicians' ratings of health or clinically observed performance-based tests as being more objective than self-report (Cousins, 1997). However, a number of studies have demonstrated that supposedly objective tests are not without bias and are not necessarily superior to more subjective ones, such as self-assessments. 
For example, in a study of individuals aged 85 years and older, Siu et al. (1993) reported acceptable validity using self-assessments of functioning. Likewise, in a sample of over 600 community-dwelling and nursing home residents aged 62 to 98 years, Cress et al. (1995) concluded that both self-reported and performancebased measurements of function were robust indicators of functional abilities in the elderly. In a study of 80 Belgian and Dutch patients with rheumatoid arthritis, Jacobs et al. (1992) also found no significant differences between functional assessments made by the physiotherapists and the patients themselves. In a comparison of self-assessments and observer-raters in the performance of 14 IADL tasks among a group of elderly subjects aged 60 to 90 years, Myers et al. (1993) reported that the self-assessments were consistent with observers' scores. Researchers have also noted that self-rated ability in the performance of ADLs and IADLs tends to be more accurate than reports from caregivers. In a study of 73 patients aged 60 years and older, who were hospitalized with acute medical or surgical problems, Elam et al. (1991) compared self-ratings of five ADLs to the ratings made by the patients' family members and physicians and found that the ratings of the patients and physicians were superior to those of family members. Dorevitch et al. (1992) reached similar conclusions from a study of 150 elderly patients at a geriatric day hospital, reporting that self-ratings of ADLs were more consistent with performance tests than ratings made by formal or informal caregivers of the patients. 
Cousins (1997) compared two subjective and two objective health assessment instruments in a sample of women aged 70 years and older. The two subjective instruments were self-reports, and the objective assessments were based on medical symptoms and the number of medications prescribed.

Significant levels of concurrent validity were found for all four instruments.

Self-reported Health Status in the Elderly. Studies have shown that selfreported health is an important indicator of a person's overall health status. In populational studies, self-reported health measures have been found to be significant predictors of mortality (Idler and Benyamini, 1997; Rakowski et al., 1991; Wolinsky and Johnson, 1922; Bernard et al., 1997). In a review of twentyseven longitudinal studies of health status in adult populations from the US and abroad, Idler and Benyamini (1997) concluded that global self-assessment of health status remained an independent predictor of mortality, even after controlling for other possible co-variants, such as socioeconomic status, life satisfaction, health practices, social networks, and social support systems. They found that, in most studies, the odds ratio of mortality increased between 1.5 to 3.0 times in those who rated their health the least favorably versus those who rated their health the most favorably. They also found that in five of seven studies that compared gender differences, the prediction of mortality based on self-rated health was stronger for males than for females.

In studies of the elderly, researchers have also linked self-reported health to functional status (Hoeymans et al., 1997; Krause and Jay, 1994; Lungren et al., 
1994; Hays et al., 1996; Spiers et al. 1996; Bernard et al. 1997). Longitudinal studies of the elderly have found that poor self-reported health is a significant predictor of functional decline (Grand et al., 1988; Idler and Kasl, 1995; Kaplan et al, 1993; Mor et al., 1994; Jagger et al., 1993; Wilcox et al., 1996).

In some early studies of health perceptions in the elderly, data suggested the presence of an age-related decline in self-reported health status among individuals over the age of 65 years (Mossey et al., 1982; Murray et al., 1982). However, recent studies that examine elderly individuals across a broad age spectrum reveal that, in older adults, the relationship between self-reported health status becomes less clear in increasingly older age groups. For instance, some recent studies have found significant differences in the prevalence and severity rates of functional limitations in different age groups, but no significant differences in self-reported health between the age groups (Ailinger, 1989; Christenson et al., 1994; Minkler and Langhauser, 1988; Rodin and McAvay, 1992).

Other researchers have found in comparing young elderly adults to older elderly adults, older respondents tend to report better overall health than younger ones (Idler, 1993; Moum, 1992; Wolinsky and Johnson, 1993). For example, in a study of age-effects on self assessments of health, Idler (1993) found that within each health status category, the older respondents consistently reported their health status higher than the younger ones. Likewise, Johnson and Wolinsky (1993) found that in respondents who reported similar health problems, the older 
respondents reported better self-reported health than the younger ones in a comparison of individuals 70 years of age and older from the Longitudinal Study on Aging.

Menec and Chipperfield (1997) suggest that the oldest-old, those over 85 years of age, represent a particularly unique group in that they are survivors who have lived beyond the average human life expectancy and, despite the fact the oldold and oldest-old tend to experience more physiological problems and physical limitations than the young-old, their perceptions regarding their health status may not be necessarily lower, if they are able to maintain a sense of control.

Some researchers have speculated that older adults may not regard the presence of functional limitations as necessarily affecting their quality of life if they are able to adapt to the changes in functional status (Bernard et al., 1997). Still others have suggested that many elderly individuals may accept declines in functional abilities as an unavoidable consequence of aging and not as a sign of deteriorating health and have proposed that in increasingly older adults, selfreported health may be influenced more by attitudes than by physical limitations (Borawski et al. 1996; Idler, 1993; Koval and Dobie, 1996).

\section{Theoretical Foundation of this Study}

The Disablement Process. In 1994, Verbrugge and Jette introduced a conceptual framework, which they termed "The Disablement Process", to explain the consequences of disease processes on functional abilities. This model, which is an extension of Nagi's disability scheme and the World Health Organization's 
International Classification of Impairments, Disabilities and Handicaps attempts to clarify the definitions of and delineate the differences between "pathology", "impairment", "functional limitation", and "disability". According to Verbrugge and Jette (1994), these terms, which are commonly used to describe a person's response to injury and disease, are often operationally defined in different ways by different researchers. This has led to a certain degree of ambiguity in the medical literature and to the inability to compare the results from various research groups. Verbrugge and Jette (1994) proposed the Disablement Process as a theoretical framework for conceptualizing the development of a disability in a systematic fashion.

According to the Disablement Process, the primary pathway for the development of disability occurs along a continuum in four successive stages: (a) pathology, (b) impairment, (c) functional limitation, and (d) disability. Pathology leads to impairments, which in turn produce functional limitations, and functional limitations eventually lead to the development of a disability. Pathology is defined as biochemical or physiological abnormalities which result from disease processes, injury or developmental conditions. Impairments are the dysfunctions of bodily systems which result from pathology. Functional limitations are the restrictions a person has in performing physical or mental actions which produce tasks. Disability is defined in terms of a person's difficulty in the performance of purposeful tasks independently within the context of the person's own 
environment. For example, difficulty in walking is considered a functional limitation and the inability to perform light housework is considered a disability. According to Verbrugge and Jette (1994), the Disablement Process is one model that can be particularly useful in explaining the forms of disabilities that develop over long periods of time and are associated with chronic diseases. These are the types of disabilities most often seen in older adults. The model can also be used in the interpretation of data from health surveys regarding functional abilities that address a person's ability to independently perform basic activities of daily living, including self-care and home-maintenance tasks, without assistance from another person or mechanical device and operationally define "disability" as the level of difficulty in the performance of activities of daily living (ADLs) and instrumental activities of daily living (IADLs) (Verbrugge and Jette, 1994).

Model of Human Occupation. The Model of Human Occupation (MOHO) can be used as a framework to examine the relationship between self-reported health and functional abilities in different age groups of elderly individuals. It is one theory in Occupational Therapy formulated as a basis for understanding and conceptualizing the performance of human occupational behavior (purposeful activity) (Kielhofner and Forsyth, 1997). According to MOHO, which evolved out of the general systems theory, human beings are viewed as dynamic open systems that produce and are affected by occupational behavior (purposeful activity) and the environment. The structure of the human system consists of three heterarchically-arranged subsystems: the volition subsystem, the 
habituation subsystem, and the mind-brain-body performance subsystem. Each of these subsystems provides unique contributions to the operation of the system as a whole, and they interact with one another and the environment to produce behavior. However, a change or disruption in any of the three subsystems or in their interactions with the environment can lead to a change in functional abilities. According to MOHO, personal causation, one of the components of the volition subsystem, includes the concepts of self-knowledge or personal awareness of one's own capacities. Personal causation influences and, in turn, is influenced by a person's functional abilities. Maintaining a belief in one's abilities can have a profound influence on performance skills. The relationship between volition and functional abilities may be especially important in the elderly who may be challenged by increasing physical limitations caused by physiological changes associated with the normal aging process, as well as those associated with chronic health conditions. In order to psychologically adapt to limitations caused by diminishing physical capacities resulting from the biological aging process, it may be necessary to alter one's volitional system, which includes altering how one measures his or her own health status.

In applications of occupational therapy with the elderly, the development of successful intervention strategies relies on an accurate understanding of the perceptions of the client. Occupational therapy stresses the importance of understanding the influences that psychological, environmental and biological factors have on individual performance and quality of life. In working with the 
elderly it is particularly important to understand that these influences are dynamic processes and the influence of each on a person's health and well-being may continue to change as the person ages. 


\section{CHAPTER III}

\section{METHODOLOGY}

The data used in this study were taken from the Comprehensive Needs Assessment Survey of Elders 60 years and older in Dade County conducted by the Southeast Florida Center on Aging at Florida International University between August 1993 and October 1994 and funded by the Alliance for Aging, Inc., the area agency on aging for Dade and Monroe Counties (Condon et al., 1994). The three primary objectives of the survey were to document the needs and attitudes of the elderly living in Dade County for resource and services planning, to provide data for health-care related research and to provide information on the effects of Hurricane Andrew on the elderly population.

Information for the Needs Assessment Survey was received from three sources: (a) ten focus groups, (b) a survey of 48 key informants, and (c) a survey of 1992 elders. The survey of 1992 elders was composed of a representative sample of $0.5 \%$ of the population aged 60 years and older living in Dade County. The 1992 elders were surveyed by telephone and in face-to-face interviews using a formal questionnaire developed by the Southeast Florida Center on Aging.

The questionnaire contained 155 questions regarding present and future concerns, physical health, emotional health, life satisfaction, functional abilities in the performance of activities of daily living (ADLs) and instrumental activities of daily living (IADLs), mobility status, utilization and knowledge of health care 
services, participation in social activities, nutritional status and needs, the impact of Hurricane Andrew, and socio-demographic information.

The data for this study were taken from the responses to the questionnaire. The purpose of this study was to compare the relationship between self-reported health perceptions and functional abilities in four age groups (60 to 64 years old, 65 to 74 years old, 75 to 84 years old, and 85 years and older) of elderly individuals in Dade County, Florida.

The following research questions were investigated:

(1) Is there a relationship between self-reported health and age of the elderly?

(2) Is there a relationship between self-reported functional ability and age of the elderly?

(3) Is there a relationship between self-reported health and self-reported functional ability of the elderly?

(4) Does the relationship between self-reported health and self-reported functional ability differ among four age groups of elderly individuals?

\section{$\underline{\text { Subjects }}$}

The sample that was used for this study consisted of the 1971 elders who reported their age in the Comprehensive Needs Assessment Survey of Elders 60 years and older in Dade County. There were 1992 respondents in the total sample which was composed of a random sample of 1892 individuals interviewed by telephone and a convenience sample of 100 low-income individuals who lacked 
telephones and were interviewed in person. The sample constituted a representative sample of the population aged 60 years and older living in Dade County.

The telephone survey was conducted from October, 1993 through September, 1994 by professionally-trained interviewers from the Institute for Public Opinion Research at Florida International University working with the Southeast Florida Center on Aging. Prior to conducting the survey, all of the interviewers received special formal instruction relating to issues of cultural sensitivity and the administration of surveys to elderly individuals. Based on the preference of the respondent, the interviews were conducted in either English or Spanish.

The 1892 subjects in the telephone survey were selected using a sampling frame which produced a random selection of telephone numbers from a representative sample of the population with listed or unlisted telephones in Dade County. The sampling frame consisted of dividing the survey area into ten subareas and then generating a list of random telephone numbers for each sub-area.

In order to produce a representative sample of 1892 elderly individuals, a total of 33,404 telephone numbers were used. Each number was called a maximum of five times at various times during the day and night. If a person aged 60 years or older resided at the number and consented to the survey, the interview was conducted. There were 171 cases where the elder was unable to answer the questions because of a physical or mental condition. In these cases, a 
proxy, who was familiar enough with the elder to provide answers on his or her behalf, was interviewed.

In addition to the telephone survey, a face-to-face survey was conducted of low-income and minority individuals who did not have access to a telephone. The purpose of this survey was to compensate for the possible under-representation of this group in the telephone survey. Because there was no official list of such individuals in existence with which a random sample could be extracted, a convenience sample of 100 individuals lacking telephones was selected from four minority and low-income neighborhoods. The sample consisted of 50 AfricanAmerican individuals who were interviewed at four nutrition and community activity centers and 50 Hispanic individuals who were interviewed at two housing complexes for the elderly.

According to figures from the 1990 US Census, the sample consisted of $0.5 \%$ of the total population aged 60 years and older living in Dade County and was representative of that population. The composition of the sample by age group was $22.8 \%$ aged 60 to 64 years, $44.8 \%$ aged 65 to 74 years, $24.9 \%$ aged 75 to 84 years, and $7.5 \%$ aged 85 years and over. By ethnic group, the sample is $39.8 \%$ white non-Hispanic, 37.5\% Cuban Hispanic, 11.1\% African-American non-Hispanic, $10.5 \%$ non-Cuban Hispanic, and $1.1 \%$ other ethnic group.

The 1971 subjects used for this study were divided into the following four age categories: 60 to 64 years old, 65 to 74 years old, 75 to 84 years old, and 85 years and older. The numbers in each category were as follows: 456 subjects aged 
60 to 64 years, 887 subjects aged 65 to 74 years, 487 subjects aged 75 to 84 years, and 141 subjects 85 years and older.

Procedure

Prior to beginning the study, Dr. Gail Hills received permission from the Southeast Florida Center on Aging at Florida International University to use the dataset. A computerized copy of the data was transferred to the student's mainframe computer account and where it was sorted and appropriate statistical analyses were conducted using the statistical package, Statistical Package for the Social Sciences (SPSS).

\section{Instrument}

The instrument that was used in this study was a questionnaire designed by the Southeast Florida Center on Aging at Florida International University as the survey instrument for the Needs Assessment Survey of Elders in Dade County. Its primary purpose was to collect information concerning the needs, concerns, abilities and limitations of the elderly. Prior to developing the survey instrument, the Center on Aging conducted meetings with ten focus groups consisting of area elderly citizens, informal caregivers, service providers and other interested parties, who provided input regarding the selection of questions which would be culturally sensitive and relative to the needs and interests of the culturally diverse groups which made up the targeted survey population.

The final questionnaire contained 155 questions regarding the subjects' present and future concerns, physical health, emotional health, life satisfaction, 
functional abilities in the performance of ADLs and IADLs, mobility status, utilization and knowledge of health care services, participation in social activities, nutritional status and needs, and the impact of Hurricane Andrew. The questionnaire also requested socio-demographic information including age, gender, ethnicity, employment status, marriage status, educational level and income.

In this study, the following questions regarding socio-demographic information were used: age (question 129), gender (question 1), racial group (question 137), whether or not the respondent considered himself or herself Hispanic (question 138), country of birth (question 139), level of education (question 141), marital status (130), and personal income (question 144).

Question 7, which is "Compared to others your age, how would you rate your overall health?" was used in the study to evaluate self-reported health status. For each $\mathrm{ADL}$ and IADL, there were a pair of questions which related to the level of difficulty in the performance of the activity. The first question asked "Because of a health problem, do you have difficulty with (the specified ADL or IADL)?" If the subject responded with "yes", then the subject was asked to rate the level of difficulty on a three-level scale (some difficulty, a lot of difficulty, or completely unable). These pairs of questions for each ADL and IADL were used in this study. The following ADLs with their respective pairs of questions were used: bathing (questions 63 and 64), dressing (questions 67 and 68), eating (questions 71 and 72), taking care of appearance (questions 79 and 80), toileting 
(questions 83 and 84), transferring (questions 87 and 88), getting up and down stairs (questions 91 and 92), and walking (question 95 and 96). The following IADLs with their respective pairs of questions were used: taking medications (questions 75 and 76), preparing meals (questions 99 and 100), shopping (questions 102 and 103), managing money (questions 105 and 106), using the telephone (questions 108 and 109), doing laundry (questions 111 and 112), doing other housework (questions 114 and 115), and getting to places in the community (questions 117 and 118).

\section{Data Analysis}

For purposes of data analysis, the subjects were assigned to one of the following four age groups: (a) youngest-old (60 to 64 years old), (b) young-old (65 to 74 years old), (c) old-old ( 75 to 84 years old) and (d) oldest-old (85 years old and over). There were 456 subjects aged 60 to 64 years, 887 subjects aged 65 to 74 years, 487 subjects aged 75 to 84 years, and 141 subjects over 85 years of age. Frequencies and percentages for each of the socio-demographic variables in each of the four age groups were determined. For all calculations, comparisons across age groups by gender were also made. All calculations were tested for statistical significance using a level of significance of $\mathrm{p}<.05$.

To answer research question 1 , frequencies and percentages of the four possible answers (excellent, good, fair, or poor) to question 7 , which was "Compared to others your age, how would you rate your overall health?" were calculated by age group. Chi-square tests were used to compare the frequencies for the four age groups. 
To answer research question 2, using the pairs of questions of each of the eight ADLs (bathing, dressing, eating, taking care of appearance, toileting, transferring, getting up and down stairs, and walking) and eight IADLs (taking medications, preparing meals, shopping, managing money, using the telephone, doing laundry, doing other housework, and getting to places in the community), the level of difficulty for each ADL and IADL was converted to a four-point Likert scale as follows: $0=$ "no difficulty performing activity", 1 = "some difficulty", 2 = "a lot of difficulty", 3 = "completely unable to perform activity". Frequencies and percentages of level of difficulty for each ADL and IADL by age were then determined. Chi-square tests were used to compare the frequencies for the four age groups. Analysis of variance tests were performed to compare the mean number of ADLs they had difficulty with among the four age groups. Analysis of variance tests were performed to compare the mean number of IADLs they had difficulty with among the four age groups.

To answer research question 3, a Pearson's correlation coefficient was calculated to determine whether there was a statistically significant relationship between self-reported health and the number of ADLs with which they have difficulty. Similarly, a Pearson's correlation coefficient was calculated to determine whether there was a statistically significant relationship between selfreported health and the number of IADLs with which they had difficulty.

To answer research question 4, Pearson's correlations between selfreported health status and the number of ADLs with which they had difficulty for 
each of the four age groups were compared to one another using a $z$-test.

Similarly, Pearson's correlations between self-reported health status and the number of IADLs with which they had difficulty for each of the four age groups were compared to one another using a z-test.

\section{$\underline{\text { Limitations }}$}

Limitations of this study were: (a) those of the Comprehensive Needs Assessment Survey of Elders in Dade County, which included the fact that the survey was a cross-sectional study and may have contained biases caused by time of measurement or cohort effect; and (b) the data was not collected independently for the purposes of answering the research questions posed in this study. 


\section{CHAPTER IV}

\section{RESULTS}

This study examined the following four research questions: (a) Is there a relationship between self-reported health and age of the elderly? (b) Is there a relationship between self-reported functional ability and age of the elderly? (c) Is there a relationship between self-reported health and self-reported functional ability of the elderly? (d) Does the relationship between self-reported health and self-reported functional ability differ among four age groups of elderly individuals?

Demographics of the study

The sample for this study was taken from the data set of 1992 elder surveys from the Comprehensive Needs Assessment Survey of Elders 60 years and older in Dade County conducted between August 1993 and October 1994. The sample was a representative sample of $0.5 \%$ of the total population aged 60 years and older living in Dade County. This study examined the 1971 respondents who reported their age.

According to the survey results, the mean age of the 1971 elder surveys was 71.5 years. Forty-six percent of the respondents were married, $64.2 \%$ were female, $63.9 \%$ had graduated from high school, and $62.9 \%$ had an annual income of less than $\$ 20,000$. The composition of the sample by ethnic group was: $44.7 \%$ White non-Hispanic, 34.0\% Cuban, 10.7\% Black non-Hispanic, and 9.4\% non- 
Cuban Hispanic. By age group, the sample consisted of: $22.9 \%$ aged 60 to 64 years, $44.5 \%$ aged 65 to 74 years, $24.4 \%$ aged 75 to 84 years, and $7.1 \%$ aged 85 years and over. Twenty-one respondents ( $1.1 \%$ of the sample) did not report an age.

Demographics of the four age groups

To answer the questions examined in the study, the sample was divided into the following four age groups: (a) 60 to 64 years, (b) 65 to 74 years, (c) 75 to 84 years, and (d) 85 years and older. Those not reporting their ages were omitted. The age distribution of the study sample is shown in Table 1.

Table 1

Age Distribution of Study Sample

\begin{tabular}{lcr}
\hline Age Group & $\underline{\mathrm{n}}$ & $\%$ \\
\hline 60-64 years & 456 & 23.1 \\
65-74 years & 887 & 45.0 \\
75-84 years & 487 & 24.7 \\
85+ years & 141 & 7.2 \\
Total & 1971 & 100.0 \\
\hline
\end{tabular}

Demographic characteristics of the four age groups were compared using chi-square analyses. The demographic variables examined were gender, ethnicity, level of education, and income. The results of the analyses are described below. 
Comparison of gender by age. Chi-square analysis revealed that there was a significant difference between the distribution of males and females in the four age groups, $\mathrm{p}<.001$, (see Table 2 ). The percentage of females gradually increased with age from $57.5 \%$ in the 60 to 64 years age group to $74.5 \%$ in the 85 years and older age group.

Table 2

Gender Distribution by Age Group

\section{Age Group}

\begin{tabular}{llll}
\hline $60-64 \mathrm{yrs}$ & $65-74 \mathrm{yrs}$ & $75-84 \mathrm{yrs}$ & $85+\mathrm{yrs}$
\end{tabular}

\begin{tabular}{|c|c|c|c|c|c|c|c|c|}
\hline \multirow[b]{2}{*}{ Gender } & \multirow[b]{2}{*}{$\underline{\mathrm{n}}$} & \multirow[b]{2}{*}{$\%$} & \multirow[b]{2}{*}{$\underline{\mathrm{n}}$} & \multirow[b]{2}{*}{$\%$} & \multirow[b]{2}{*}{$\underline{n}$} & \multirow[b]{2}{*}{$\%$} & \multirow[b]{2}{*}{$\underline{\mathrm{n}}$} & \multirow[b]{2}{*}{$\%$} \\
\hline & & & & & & & & \\
\hline Male & 194 & 42.5 & 335 & 37.8 & 140 & 28.7 & 36 & 25.5 \\
\hline Female & 262 & 57.5 & 552 & 62.2 & 347 & 71.3 & 105 & 74.5 \\
\hline Total & 456 & 100.0 & 887 & 100.0 & 487 & 100.0 & 141 & 100.0 \\
\hline
\end{tabular}

Note. $\underline{X}^{2}(3, \underline{N}=1971)=27.54, \underline{p}<.001$

Comparison of ethnicity by age. Distributions of ethnicity differed significantly for the four age groups, $\mathfrak{p}<.001$, (see Table 3 ). The percentage of White non-Hispanics was greater in the two older age groups (51.1\% and $54.6 \%)$ than in the two younger groups $(43.0 \%$ and $40.6 \%)$ whereas the percentage of Black non-Hispanics was lower, $8.2 \%$ and $4.3 \%$ versus $15.0 \%$ and $10.8 \%$, respectively. The percentage of Cubans fluctuated with age and was higher in the age groups 65 to 74 years and 75 to 84 years ( $37.5 \%$ and $33.5 \%$, respectively) 
than in the age groups 60 to 64 years and 85 years and older $(29.7 \%$ and $27.7 \%$, respectively). The percentage of non-Cuban Hispanics also fluctuated with age but was higher in the age groups 60 to 64 years (11.0\%) and 85 years and older $(12.1 \%)$ than in the age groups 65 to 74 years $(9.9 \%)$ and 75 to 84 years $(6.4 \%)$.

Table 3

Ethnic Distribution by Age Group

\begin{tabular}{|c|c|c|c|c|c|c|c|c|}
\hline \multirow[b]{3}{*}{ Ethnicity } & \multicolumn{8}{|c|}{ Age Group } \\
\hline & \multicolumn{2}{|c|}{$60-64$ yrs } & \multicolumn{2}{|c|}{$65-74$ yrs } & \multicolumn{2}{|c|}{$75-84$ yrs } & \multicolumn{2}{|c|}{$85+$ yrs } \\
\hline & $\underline{n}$ & $\%$ & $\underline{\mathrm{n}}$ & $\%$ & $\underline{n}$ & $\%$ & $\underline{n}$ & $\%$ \\
\hline $\begin{array}{l}\text { White Non- } \\
\text { Hispanic }\end{array}$ & 195 & 43.0 & 360 & 40.6 & 249 & 51.1 & 77 & 54.6 \\
\hline $\begin{array}{l}\text { Black Non- } \\
\text { Hispanic }\end{array}$ & 68 & 15.0 & 96 & 10.8 & 40 & 8.2 & 6 & 4.3 \\
\hline $\begin{array}{l}\text { Other Non- } \\
\text { Hispanic }\end{array}$ & 6 & 1.3 & 10 & 1.1 & 4 & 0.8 & 2 & 1.4 \\
\hline Cuban & 135 & 29.7 & 333 & 37.5 & 163 & 33.5 & 39 & 27.7 \\
\hline $\begin{array}{l}\text { Non-Cuban } \\
\text { Hispanic }\end{array}$ & 50 & 11.0 & 88 & 9.9 & 31 & 6.4 & 17 & 12.1 \\
\hline Total & 454 & 100.0 & 887 & 100.0 & 487 & 100.0 & 141 & 100.0 \\
\hline
\end{tabular}


Comparison of level of education by age. The distributions of education

levels among the four age groups were significantly different, $\mathrm{p}<.002$, (see Table

4). The level of education was higher in younger groups than in the older ones.

For example, the percentage of respondents with college or graduate degrees was higher in the younger age groups than two older age groups, $28.2 \%$ and $23.2 \%$ versus $14.6 \%$ and $17.7 \%$. In addition, the percentage of respondents with no more than a high school education gradually increased with age from $20.4 \%$ in the 60 to 64 years group to $30.6 \%$ in the 85 years and older group.

Table 4

Distribution of Highest Level of Education by Age Group

\begin{tabular}{|c|c|c|c|c|c|c|c|c|}
\hline \multirow[b]{3}{*}{ Education } & \multicolumn{8}{|c|}{ Age Groups } \\
\hline & \multicolumn{2}{|c|}{$60-64$ yrs } & \multicolumn{2}{|c|}{$65-74$ yrs } & \multicolumn{2}{|c|}{$75-84$ yrs } & \multicolumn{2}{|c|}{$85+\mathrm{yrs}$} \\
\hline & $\underline{n}$ & $\%$ & $\underline{n}$ & $\%$ & $\underline{\mathrm{n}}$ & $\%$ & $\underline{\mathrm{n}}$ & $\%$ \\
\hline Grade School & 92 & 20.4 & 224 & 25.7 & 137 & 29.0 & 38 & 30.6 \\
\hline $\begin{array}{l}\text { Some High } \\
\text { School }\end{array}$ & 48 & 10.7 & 82 & 9.4 & 59 & 12.5 & 13 & 10.5 \\
\hline $\begin{array}{l}\text { High School } \\
\text { Graduate }\end{array}$ & 100 & 22.2 & 193 & 22.2 & 121 & 25.6 & 30 & 24.2 \\
\hline Some College & 83 & 18.4 & 170 & 19.5 & 87 & 18.4 & 21 & 16.9 \\
\hline College Graduate & 87 & 19.3 & 135 & 15.5 & 44 & 9.3 & 16 & 12.9 \\
\hline Graduate Degree & 40 & 8.9 & 67 & 7.7 & 25 & 5.3 & 6 & 4.8 \\
\hline Total & 450 & 100.0 & 871 & 100.0 & 473 & 100.0 & 124 & 100.0 \\
\hline
\end{tabular}


Comparison of income by age. The distributions of annual income among the four age groups were significantly different, $\mathfrak{p}<.001$, (see Table 5 ). The annual income was higher in younger groups than in the older ones. The percentage of respondents with an annual income of $\$ 20,000$ or less increased with age from $49.5 \%$ in the youngest group to $74.9 \%$ in the oldest group. The highest percentage of respondents with an annual income of less than $\$ 5,000$ was in the oldest age group (18.4\%), those 85 years and older. In contrast, the highest percentage of respondents with an annual income of over $\$ 70,000$ was in youngest age group (10.6\%), those 60 to 64 years of age. 
Table 5

Distribution of Annual Income by Age Group

\begin{tabular}{|c|c|c|c|c|c|c|c|c|}
\hline \multirow[b]{3}{*}{ Income } & \multicolumn{8}{|c|}{ Age Group } \\
\hline & \multicolumn{2}{|c|}{$60-64$ yrs } & \multicolumn{2}{|c|}{$65-74$ yrs } & \multicolumn{2}{|c|}{$75-84$ yrs } & \multicolumn{2}{|c|}{$85+y r s$} \\
\hline & $\underline{\mathrm{n}}$ & $\%$ & $\underline{\mathrm{n}}$ & $\%$ & $\underline{\mathrm{n}}$ & $\%$ & $\underline{\mathrm{n}}$ & $\%$ \\
\hline$<\$ 5,000$ & 38 & 10.9 & 98 & 15.5 & 54 & 17.3 & 14 & 18.4 \\
\hline$\$ 5-10,000$ & 56 & 16.0 & 155 & 24.6 & 106 & 33.9 & 28 & 36.8 \\
\hline$\$ 10-20,000$ & 79 & 22.6 & 161 & 25.5 & 57 & 18.2 & 15 & 19.7 \\
\hline$\$ 20-30,000$ & 44 & 12.6 & 80 & 12.7 & 38 & 12.1 & 7 & 9.2 \\
\hline$\$ 30-50,000$ & 64 & 18.3 & 70 & 11.1 & 28 & 8.9 & 6 & 7.9 \\
\hline$\$ 50-70,000$ & 32 & 9.1 & 26 & 4.1 & 12 & 3.8 & 2 & 2.6 \\
\hline$>\$ 70,000$ & 37 & 10.6 & 41 & 6.5 & 18 & 5.8 & 4 & 5.3 \\
\hline Total & 350 & 100.0 & 631 & 100.0 & 313 & 100.0 & 76 & 100.0 \\
\hline
\end{tabular}


$\underline{\text { Research question one: Is there a relationship between self-reported health and }}$ age of the elderly?

In this study, self-reported health was measured by the response to question 7 of the survey questionnaire, "Compared to others your age, how would you rate your overall health?" The respondents were given four choices to rate their health. They were asked to rate their health as "excellent", "good", "fair" or "poor". The distributions of self-reported health ratings among the four age groups were significantly different, $\mathrm{p}<.002$, (see Table 6 ). In all age groups, at least $60 \%$ of the respondents rated their health as either "excellent" or "good". However, there was a gradual decrease with age in the percentage of individuals who rate their health as "excellent" or "good". This percentage decreased from $68.1 \%$ in the 60 to 64 years age group to $60.7 \%$ in the 85 years and older group. 
Table 6

Distribution of Self-Reported Health by Age Group

\begin{tabular}{|c|c|c|c|c|c|c|c|c|}
\hline \multirow[b]{3}{*}{ Health Rating } & \multicolumn{8}{|c|}{ Age Group } \\
\hline & \multicolumn{2}{|c|}{$60-64$ yrs } & \multicolumn{2}{|c|}{$65-74$ yrs } & \multicolumn{2}{|c|}{$75-84$ yrs } & \multicolumn{2}{|c|}{$85+y r s$} \\
\hline & $\underline{\mathrm{n}}$ & $\%$ & $\underline{\mathrm{n}}$ & $\%$ & $\underline{\mathrm{n}}$ & $\%$ & $\underline{\mathrm{n}}$ & $\%$ \\
\hline Excellent & 152 & 33.7 & 258 & 29.3 & 106 & 22.0 & 26 & 18.6 \\
\hline Good & 157 & 34.8 & 351 & 39.9 & 190 & 39.5 & 59 & 42.1 \\
\hline Fair & 87 & 19.3 & 197 & 22.4 & 141 & 29.3 & 38 & 27.1 \\
\hline Poor & 55 & 12.2 & 74 & 8.4 & 44 & 9.1 & 17 & 12.1 \\
\hline Total & 451 & 100.0 & 880 & 100.0 & 481 & 100.0 & 140 & 100.0 \\
\hline
\end{tabular}

Note. $\underline{X}^{2}(9, \underline{N}=1952)=25.94, \underline{p}<.002$ 
Relationship of self-reported health and age by gender. Examinations of males and females separately found the distributions of self-reported health ratings among the four age groups were significantly different in both sexes, (in males, $\mathfrak{p}<.023$ and in females, $\mathfrak{p}<.018$ ) (see Table 7). In both sexes, favorable self-reported health ratings declined with age. For example, the percentage of respondents rating their health as "excellent" or "good" decreased from $66.3 \%$ to $60.5 \%$ for females and from $71.5 \%$ to $61.1 \%$ in males from age group 60 to 64 years to age group 85 years and older. 
Table 7

Distribution of Self-Reported Health by Age Group and Gender

$\underline{\text { Males }}$

\begin{tabular}{|c|c|c|c|c|c|c|c|c|}
\hline \multirow[b]{3}{*}{ Health Rating } & \multicolumn{8}{|c|}{ Age Group } \\
\hline & \multicolumn{2}{|c|}{$60-64$ yrs } & \multicolumn{2}{|c|}{$65-74$ yrs } & \multicolumn{2}{|c|}{$75-84$ yrs } & \multicolumn{2}{|c|}{$85+$ yrs } \\
\hline & $\underline{n}$ & $\%$ & $\underline{\mathrm{n}}$ & $\%$ & $\underline{\mathrm{n}}$ & $\%$ & $\underline{n}$ & $\%$ \\
\hline Excellent & 70 & 36.3 & 116 & 34.7 & 35 & 25.2 & 9 & 25.0 \\
\hline Good & 68 & 35.2 & 136 & 40.7 & 52 & 37.4 & 13 & 36.1 \\
\hline Fair & 31 & 16.1 & 64 & 19.2 & 37 & 26.6 & 9 & 25.0 \\
\hline Poor & 24 & 12.4 & 18 & 5.4 & 15 & 10.8 & 5 & 13.9 \\
\hline Total & 193 & 100.0 & 334 & 100.0 & 139 & 100.0 & 36 & 100.0 \\
\hline
\end{tabular}

$\underline{\text { Females }}$

Age Group

\begin{tabular}{|c|c|c|c|c|c|c|c|c|}
\hline \multirow[b]{2}{*}{ Health Rating } & \multicolumn{2}{|c|}{$60-64$ yrs } & \multicolumn{2}{|c|}{$65-74$ yrs } & \multicolumn{2}{|c|}{$75-84$ yrs } & \multicolumn{2}{|c|}{$85+y r s$} \\
\hline & $\underline{\mathrm{n}}$ & $\%$ & $\underline{\mathrm{n}}$ & $\%$ & $\underline{\mathrm{n}}$ & $\%$ & $\underline{\mathrm{n}}$ & $\%$ \\
\hline Excellent & 82 & 31.8 & 142 & 26.0 & 71 & 20.8 & 17 & 16.3 \\
\hline Good & 89 & 34.5 & 215 & 39.4 & 138 & 40.4 & 46 & 44.2 \\
\hline Fair & 56 & 21.7 & 133 & 24.4 & 104 & 30.4 & 29 & 27.9 \\
\hline Poor & 31 & 12.0 & 56 & 10.3 & 29 & 8.5 & 12 & 11.5 \\
\hline Total & 258 & 100.0 & 546 & 100.0 & 342 & 100.0 & 104 & 100.0 \\
\hline
\end{tabular}

Note. $X^{2}(9, \underline{N}=1250)=19.92, \underline{p}<.018$ 
Research question two: Is there a relationship between self-reported functional ability and age of the elderly?

In the study, self-reported functional abilities were measured by the responses to a pair of questions about each of the eight ADLs and eight IADLs addressed in the survey. The first question regarded the presence or absence of difficulty with an ADL or IADL and asked, "Because of a health problem, do you have difficulty with (a specified ADL or IADL)?" For each ADL and IADL, comparisons across age groups were made of the percentage of respondents responding "yes" to this question.

The second question regarded the level of difficulty with each of the eight ADLs and eight IADLs. If the respondent answered "yes" to the first question, the respondent was asked to rate the level of difficulty on a three-point scale: (a) some difficulty, (b) a lot of difficulty, or (c) completely unable without assistance or special equipment. For each $\mathrm{ADL}$ and IADL, comparisons by age group were made of the distributions of the three levels of difficulty.

The total number of ADLs each respondent reported difficulty with was computed and the mean numbers of difficulties with ADLs were compared across the four age groups. Similarly, the total number of IADLs each respondent reported difficulty with was computed and the mean numbers of difficulties with IADLs were then compared across the four age groups. 
Evaluation of functional ability was based on presence of difficulties, level of difficulty, numbers of difficulties, and the mean number of difficulties with ADLs and IADLs across age groups.

Presence of difficulties with ADLs in the four age groups. Each of the ADLs was compared separately across the four age groups and the results are presented in Table 8 .

There were significant differences across the four age groups in the percentage of respondents reporting difficulty with seven out of the eight ADLs covered in the survey: bathing, dressing, caring for appearance, using the toilet, getting in and out of a chair, using stairs, and walking, ps $<.001$ (see Table 8).

The percentage of respondents reporting difficulty with each of the ADLs increased with age, but the distributions were not linear. The percentage of respondents reporting difficulty with ADLs was dramatically higher in the oldest age group ( $85+$ years) in comparison with the other groups. For most ADLs, the percentage of respondents reporting difficulties was very similar in the three youngest age groups. For example, the percentages of respondents reporting difficulty with appearance in the three youngest age groups were $1.8 \%, 2.8 \%$, and $3.3 \%$, respectively, in comparison with $15.1 \%$ in the oldest group.

Across the age groups, the most frequently reported ADLs with difficulty involved mobility-related activities (getting in and out of a chair, using stairs, and walking). Thirteen percent of the total sample reported difficulty with getting in 
and out of a chair; $20.6 \%$ reported difficulty with walking; and $23.3 \%$ reported difficulty with using stairs. At least $10 \%$ of respondents in each age group reported difficulty with these activities and the percentage of respondents reporting difficulties increased with age.

Eating was the only ADL in which there was not a significant difference across the four age groups in the percentage of respondents reporting difficulty and it was also one of the least reported ADL difficulties in all four age groups. From the youngest to oldest age groups the percentages of respondents reporting difficulty with eating were $2.9 \%, 2.8 \%, 3.7 \%$ and $5.7 \%$, respectively. 
Table 8

Presence of Difficulties with ADLs by Age Group

\begin{tabular}{|c|c|c|c|c|c|c|c|c|}
\hline \multirow[b]{3}{*}{$\mathrm{ADL}$} & \multicolumn{8}{|c|}{ Age Group ${ }^{a}$} \\
\hline & \multicolumn{2}{|c|}{$60-64$ yrs } & \multicolumn{2}{|c|}{$65-74$ yrs } & \multicolumn{2}{|c|}{$75-84$ yrs } & \multicolumn{2}{|c|}{$85+$ yrs } \\
\hline & $\underline{n}$ & $\%$ & $\underline{\mathrm{n}}$ & $\%$ & $\underline{\mathrm{n}}$ & $\%$ & $\underline{\mathrm{n}}$ & $\%$ \\
\hline Bathing** & 16 & 3.5 & 64 & 7.2 & 51 & 10.5 & 39 & 27.7 \\
\hline Dressing** & 24 & 5.3 & 40 & 4.5 & 26 & 5.3 & 22 & 15.6 \\
\hline Eating & 13 & 2.9 & 25 & 2.8 & 18 & 3.7 & 8 & 5.7 \\
\hline Appearance** & 8 & 1.8 & 25 & 2.8 & 16 & 3.3 & 21 & 15.1 \\
\hline Toileting** & 12 & 2.6 & 25 & 2.8 & 16 & 3.3 & 13 & 9.2 \\
\hline $\begin{array}{l}\text { Getting in/out of a } \\
\text { chair** }\end{array}$ & 50 & 11.0 & 104 & 11.7 & 70 & 14.4 & 38 & 27.0 \\
\hline Using stairs** & 82 & 18.0 & 158 & 17.9 & 116 & 23.9 & 61 & 44.2 \\
\hline Walking** & 69 & 15.2 & 144 & 16.3 & 130 & 26.7 & 62 & 44.3 \\
\hline
\end{tabular}

Note. Chi-square tests were performed on all ADLs and the results are as follows:

Bathing, $\underline{X}^{2}(3, \underline{N}=1971)=84.31, \underline{p}<.001 ;$ dressing, $\underline{X}^{2}(3, \underline{N}=1969)=28.37$,

$\underline{p}<.001$; eating, $\underline{X}^{2}(3, \underline{N}=1968)=3.67, \underline{p}<.299$; caring for appearance,

$\underline{X}^{2}(3, \underline{N}=1967)=59.83, \underline{p}<.001 ;$ using the toilet, $\underline{X}^{2}(3, \underline{N}=1970)=16.50, \underline{p}<.001$;

getting in and out of a chair, $\underline{X}^{2}(3, \underline{N}=1969)=27.24, p<.001$; using stairs,

$\underline{X}^{2}(3, \underline{N}=1962)=54.21, \underline{p}<.001 ;$ and walking, $\underline{X}^{2}(3, \underline{N}=1967)=77.74, \underline{p}<.001$.

${ }^{a}$ The numbers and percentages in each age group responding "yes" to the question, "Because of a health problem, do you have difficulty with (the corresponding ADL)?”

$* * \underline{p}<.01$. 
Presence of difficulties with ADLs in the four age groups by gender.

Among females, the number of respondents reporting difficulties was sufficient in the four age groups to allow statistical comparisons across age groups for each of the eight ADLs and the results are presented in Table 9. The distribution of females reporting difficulties mirrored that of the entire sample for all eight ADLs. As was the case for the entire sample, there were significant differences across the four age groups in the percentage of females reporting difficulty with all ADLs except eating. In addition, the percentage of females reporting difficulty with ADLs increased with age. Again, the distribution of females reporting difficulties with ADLs was not linear and the percentage of females reporting difficulties was much higher in the oldest age group ( $85+$ years) in comparison with the other groups. 
Table 9

Presence of Difficulties with ADLs by Age Group among Females

\begin{tabular}{|c|c|c|c|c|c|c|c|c|}
\hline \multirow[b]{3}{*}{$\mathrm{ADL}$} & \multicolumn{8}{|c|}{ Age Group ${ }^{a}$} \\
\hline & \multicolumn{2}{|c|}{$60-64$ yrs } & \multicolumn{2}{|c|}{$65-74$ yrs } & \multicolumn{2}{|c|}{$75-84$ yrs } & \multicolumn{2}{|c|}{$85+y r s$} \\
\hline & $\underline{\mathrm{n}}$ & $\%$ & $\underline{n}$ & $\%$ & $\underline{\mathrm{n}}$ & $\%$ & $\underline{n}$ & $\%$ \\
\hline Bathing** & 9 & 3.4 & 48 & 8.7 & 42 & 12.1 & 33 & 31.4 \\
\hline Dressing** & 15 & 5.7 & 30 & 5.4 & 20 & 5.8 & 21 & 20.0 \\
\hline Eating & 11 & 4.2 & 14 & 2.5 & 13 & 3.7 & 8 & 7.6 \\
\hline Appearance** & 6 & 2.3 & 21 & 3.8 & 13 & 3.7 & 18 & 17.5 \\
\hline Toileting** & 6 & 2.3 & 21 & 3.8 & 13 & 3.7 & 11 & 10.5 \\
\hline $\begin{array}{l}\text { Getting in/out of a } \\
\text { chair** }\end{array}$ & 36 & 13.8 & 79 & 14.3 & 53 & 15.3 & 32 & 30.5 \\
\hline Using stairs** & 53 & 20.2 & 126 & 22.9 & 92 & 26.6 & 50 & 49.0 \\
\hline Walking** & 44 & 16.8 & 103 & 18.7 & 100 & 28.9 & 50 & 47.6 \\
\hline
\end{tabular}

Note. Chi-square tests were performed on all ADLs and the results are as follows:

Bathing, $\underline{X}^{2}(3, \underline{N}=1266)=66.12, \underline{p}<.001$; dressing, $\underline{X}^{2}(3, \underline{N}=1266)=31.59, \underline{p}<.001$;

eating, $\underline{X}^{2}(3, \underline{N}=1265)=6.89, \underline{p}<.076$; caring for appearance,

$\underline{X}^{2}(3, \underline{N}=1263)=43.50, \underline{p}<.001 ;$ using the toilet, $\underline{X}^{2}(3, \underline{N}=1266)=13.48, \underline{p}<.004$;

getting in and out of a chair, $\underline{X}^{2}(3, \underline{N}=1265)=18.77, \underline{p}<.001$; using stairs,

$\underline{X}^{2}(3, \underline{N}=1260)=35.71, \underline{p}<.001 ;$ and walking, $\underline{X}^{2}(3, \underline{N}=1265)=53.38, \underline{p}<.001$.

aThe numbers and percentages in each age group responding "yes" to the

question, "Because of a health problem, do you have difficulty with (the specified

ADL)?"

${ }^{* *} \mathrm{p}<.01$. 
Among males, the distributions of respondents reporting difficulties with ADLs were slightly different from those of females (Table 10). There were fewer males than females reporting reporting difficulties with all ADLs. The frequencies of males reporting difficulty with three ADLs (eating, taking care of appearance, and using the toilet) were too small to permit chi-square analyses across the age groups. For three of the remaining five ADLs (bathing, using stairs, and walking), there were significant differences in the percentage of males reporting difficulty across age groups. Like the females, the percentage of males reporting difficulties was highest in the oldest age group (85+ years) in comparison with the other groups for each of these ADLs. However, in comparison to females, the percentage of males reporting difficulties was lower for these three ADLs (bathing, using stairs, and walking). Unlike the females, among males, there were not significant differences across age groups for difficulties with two ADLs (dressing and getting in and out of a chair). 
Table 10

Presence of Difficulties with ADLs by Age Group among Males

\begin{tabular}{|c|c|c|c|c|c|c|c|c|}
\hline \multirow[b]{3}{*}{ ADL } & \multicolumn{8}{|c|}{ Age Group ${ }^{a}$} \\
\hline & \multicolumn{2}{|c|}{$60-64$ yrs } & \multicolumn{2}{|c|}{$65-74 \mathrm{yrs}$} & \multicolumn{2}{|c|}{$75-84$ yrs } & \multicolumn{2}{|c|}{$85+$ yrs } \\
\hline & $\underline{\mathrm{n}}$ & $\%$ & $\underline{\mathrm{n}}$ & $\%$ & $\underline{\mathrm{n}}$ & $\%$ & $\underline{\mathrm{n}}$ & $\%$ \\
\hline Bathing** & 7 & 3.6 & 16 & 4.8 & 9 & 6.4 & 6 & 16.7 \\
\hline Dressing & 9 & 4.7 & 10 & 3.0 & 6 & 4.3 & 1 & 2.8 \\
\hline Eating $^{\mathrm{b}}$ & 2 & 1.0 & 11 & 3.3 & 5 & 3.6 & 0 & 0.0 \\
\hline Appearance $^{b}$ & 2 & 1.0 & 4 & 1.2 & 3 & 2.1 & 3 & 8.3 \\
\hline Toileting ${ }^{b}$ & 6 & 3.1 & 4 & 1.2 & 3 & 2.1 & 2 & 5.6 \\
\hline $\begin{array}{l}\text { Getting in/out of a } \\
\text { chair }\end{array}$ & 14 & 7.2 & 25 & 7.5 & 17 & 12.1 & 6 & 16.7 \\
\hline Using stairs** & 29 & 15.0 & 32 & 9.6 & 24 & 17.1 & 11 & 30.6 \\
\hline Walking** & 25 & 13.0 & 41 & 12.3 & 30 & 21.4 & 12 & 34.3 \\
\hline \multicolumn{9}{|c|}{ dressing, $\underline{X}^{2}(3, \underline{N}=703)=1.19, \underline{p}<.755$; getting in and out of a chair, } \\
\hline \multicolumn{9}{|c|}{$\underline{X}^{2}(3, \underline{N}=704)=6.05, \underline{p}<.109 ;$ using stairs, $\underline{X}^{2}(3, \underline{N}=702)=15.08, \underline{p}<.002 ;$ and } \\
\hline \multicolumn{9}{|c|}{ walking, $\underline{X}^{2}(3, \underline{N}=702)=16.89, \underline{p}<.001$} \\
\hline \multicolumn{9}{|c|}{ aThe numbers and percentages in each age group responding "yes" to the } \\
\hline \multicolumn{9}{|c|}{ question, "Because of a health problem, do you have difficulty with (the specified } \\
\hline \multicolumn{9}{|l|}{ ADL)?" } \\
\hline${ }^{\mathrm{b}}$ Sample sizes insuff & ent & or chi & com & arison & & & & \\
\hline
\end{tabular}


Presence of difficulties with IADLs in the four age groups. Each of the

IADLs was compared separately across age groups with the results presented in Table 11. For each IADL, the percentage of respondents reporting difficulty was determined for the four age groups.

There were significant differences across the four age groups in the percentage of respondents reporting difficulty with all of IADLs (see Table 11).

For all of the eight IADLs, the percentage of respondents reporting difficulty increased with age. Once again, the distributions were not linear and the greatest percentage of respondents reporting difficulty with IADLs was in the oldest age group ( $85+$ years) in comparison to the other groups. There were no significant differences between the two youngest groups (60-64 years and 65-74 years).

The most frequently reported IADL with difficulty was housework and percentage of respondents reported difficulty with housework ranged from $10.1 \%$ in ages 60 to 64 years to $34.3 \%$ in ages 85 years and older. Other IADLs with high percentages of respondents reporting difficulty were shopping $(7.1 \%$ to $22.9 \%$ ), and going places in the community (6.4\% to $30.9 \%$ ) (see Table 11 ). The least reported IADL with difficulty was taking medicine and ranged from $1.3 \%$ in the youngest group to $6.4 \%$ in the oldest. 
Table 11

Presence of Difficulties with IADLs by Age Group

\begin{tabular}{|c|c|c|c|c|c|c|c|c|}
\hline \multirow[b]{3}{*}{ IADL } & \multicolumn{8}{|c|}{ Age Group ${ }^{a}$} \\
\hline & \multicolumn{2}{|c|}{$60-64$ yrs } & \multicolumn{2}{|c|}{$65-74$ yrs } & \multicolumn{2}{|c|}{$75-84$ yrs } & \multicolumn{2}{|c|}{$85+y r s$} \\
\hline & $\underline{\mathrm{n}}$ & $\%$ & $\underline{\mathrm{n}}$ & $\%$ & $\underline{\mathrm{n}}$ & $\%$ & $\underline{n}$ & $\%$ \\
\hline $\begin{array}{l}\text { Taking } \\
\text { medicine** }\end{array}$ & 6 & 1.3 & 9 & 1.0 & 8 & 1.6 & 9 & 6.4 \\
\hline Preparing meals** & 21 & 4.6 & 39 & 4.4 & 33 & 6.8 & 32 & 22.9 \\
\hline Shopping** & 32 & 7.1 & 67 & 7.6 & 72 & 14.8 & 45 & 32.1 \\
\hline $\begin{array}{l}\text { Managing } \\
\text { money** }\end{array}$ & 18 & 4.0 & 48 & 5.4 & 24 & 5.0 & 29 & 20.6 \\
\hline Using telephone** & 5 & 1.1 & 14 & 1.6 & 23 & 4.7 & 21 & 14.9 \\
\hline Doing laundry** & 15 & 3.3 & 47 & 5.3 & 28 & 5.8 & 35 & 25.0 \\
\hline $\begin{array}{l}\text { Doing } \\
\text { housework** }\end{array}$ & 46 & 10.1 & 90 & 10.2 & 69 & 14.3 & 48 & 34.3 \\
\hline $\begin{array}{l}\text { Going places in } \\
\text { community** }\end{array}$ & 29 & 6.4 & 94 & 10.6 & 64 & 13.2 & 43 & 30.9 \\
\hline
\end{tabular}

Note. Chi-square tests were performed on all IADLs and the results are as

follows: preparing meals, $\underline{X}^{2}(3, \underline{N}=1965)=72.03, \underline{p}<.001$; shopping,

$\underline{X}^{2}(3, \underline{N}=1965)=89.07, \underline{p}<.001 ;$ managing money, $\underline{X}^{2}(3, \underline{N}=1962)=57.19$,

$\underline{p}<.001$; using the telephone, $\underline{X}^{2}(3, \underline{N}=1970)=80.02, \underline{p}<.001$; doing laundry,

$\underline{X}^{2}(3, \underline{N}=1962)=90.46, \underline{p}<.001$; doing housework, $\underline{X}^{2}(3, \underline{N}=1963)=66.89$,

$\underline{p}<.001$; getting to places in the community, $\underline{X}^{2}(3, \underline{N}=1963)=64.16, \underline{p}<.001$; and

taking medicine, $\underline{X}^{2}(3, \underline{N}=1966)=22.25, \underline{p}<.001$.

aThe numbers and percentages in each age group responding "yes" to the

question, "Because of a health problem, do you have difficulty with (the

corresponding IADL)?"

${ }^{* *} \mathrm{p}<.01$. 
Presence of difficulties with IADLs in the four age groups by gender. Among both males and females, the percentage of respondents reporting difficulty with IADLs tended to increase with age (see Tables 12 and 13).

Among females, the differences across age groups were significant for all IADLs (see Table 12). In all cases, more of the oldest age group ( $85+$ years) reported difficulties with IADLs than the three younger groups.

Among males, the differences across age groups were significant for five IADLs: preparing meals, shopping, using the telephone, doing laundry, and doing housework (see Table 13). For preparing meals and doing laundry, the oldest age group ( $85+$ years) reported much higher frequencies than the three younger groups. For using the telephone and doing housework, the two groups over 75 years of age reported higher frequencies than the two groups under 75 years. There were not significant differences across the age groups for managing money and getting to places in the community. For taking medicine, the numbers of males reporting difficulty were too small for chi-square comparisons across age groups. 
Table 12

Presence of Difficulties with IADLs by Age Group among Females

\begin{tabular}{|c|c|c|c|c|c|c|c|c|}
\hline \multirow[b]{3}{*}{ IADL } & \multicolumn{8}{|c|}{ Age Group ${ }^{a}$} \\
\hline & \multicolumn{2}{|c|}{$60-64$ yrs } & \multicolumn{2}{|c|}{$65-74$ yrs } & \multicolumn{2}{|c|}{$75-84$ yrs } & \multicolumn{2}{|c|}{$85+$ yrs } \\
\hline & $\underline{\mathrm{n}}$ & $\%$ & $\underline{\mathrm{n}}$ & $\%$ & $\underline{\mathrm{n}}$ & $\%$ & $\underline{n}$ & $\%$ \\
\hline $\begin{array}{l}\text { Taking } \\
\text { medicine** }\end{array}$ & 4 & 1.5 & 7 & 1.3 & 8 & 2.3 & 9 & 8.6 \\
\hline Preparing meals** & 15 & 5.7 & 30 & 5.4 & 25 & 7.2 & 28 & 26.9 \\
\hline Shopping** & 22 & 8.4 & 60 & 10.9 & 56 & 16.2 & 41 & 39.4 \\
\hline $\begin{array}{l}\text { Managing } \\
\text { money** }\end{array}$ & 8 & 3.1 & 35 & 6.4 & 17 & 4.9 & 26 & 24.8 \\
\hline Using telephone** & 4 & 1.5 & 12 & 2.2 & 16 & 4.6 & 19 & 18.1 \\
\hline Doing laundry** & 9 & 3.4 & 40 & 7.3 & 20 & 5.8 & 30 & 28.8 \\
\hline $\begin{array}{l}\text { Doing } \\
\text { housework** }\end{array}$ & 37 & 14.1 & 75 & 13.6 & 54 & 15.7 & 43 & 41.3 \\
\hline $\begin{array}{l}\text { Going places in } \\
\text { community** }\end{array}$ & 21 & 8.0 & 72 & 13.1 & 51 & 14.7 & 39 & 37.9 \\
\hline
\end{tabular}

Note. Chi-square tests were performed on all IADLs and the results are as follows: preparing meals, $\underline{X}^{2}(3, \underline{N}=1263)=59.28, \underline{p}<.001$; shopping, $\underline{X}^{2}(3, \underline{N}=1262)=67.58, \underline{p}<.001 ;$ managing money, $\underline{X}^{2}(3, \underline{N}=1263)=61.24$, $\mathrm{p}<.001$; using the telephone, $\underline{X}^{2}(3, \underline{N}=1265)=63.16, \underline{p}<.001$; doing laundry, $\underline{X}^{2}(3, \underline{N}=1263)=72.88, \underline{p}<.001$; doing housework, $\underline{X}^{2}(3, \underline{N}=1261)=51.03$, $\mathrm{p}<.001$; getting to places in the community, $\underline{X}^{2}(3, \underline{N}=1262)=55.04, \underline{p}<.001$; and taking medicine, $\underline{X}^{2}(3, \underline{N}=1263)=22.41, \underline{p}<.001$.

aThe numbers and percentages in each age group responding "yes" to the question, "Because of a health problem, do you have difficulty with (the corresponding IADL)?" $* * \mathrm{p}<.01$. 
Table 13

Presence of Difficulties with IADLs by Age Group among Males

\begin{tabular}{|c|c|c|c|c|c|c|c|c|}
\hline \multirow[b]{3}{*}{ IADL } & \multicolumn{8}{|c|}{ Age Group ${ }^{\mathrm{a}}$} \\
\hline & \multicolumn{2}{|c|}{$60-64$ yrs } & \multicolumn{2}{|c|}{$65-74$ yrs } & \multicolumn{2}{|c|}{$75-84$ yrs } & \multicolumn{2}{|c|}{$85+$ yrs } \\
\hline & $\underline{\mathrm{n}}$ & $\%$ & $\underline{\mathrm{n}}$ & $\%$ & $\underline{\mathrm{n}}$ & $\%$ & $\underline{\mathrm{n}}$ & $\%$ \\
\hline Taking medicine & 2 & 1.0 & 2 & $\overline{0.6}$ & 0 & 0.0 & 0 & 0.0 \\
\hline Preparing meals** & 6 & 3.1 & 9 & 2.7 & 8 & 5.7 & 4 & 11.1 \\
\hline Shopping** & 10 & 5.2 & 7 & 2.1 & 16 & 11.4 & 4 & 11.1 \\
\hline Managing money & 10 & 5.2 & 13 & 3.9 & 7 & 5.1 & 3 & 8.3 \\
\hline Using telephone** & 1 & 0.5 & 2 & 0.6 & 7 & 5.0 & 2 & 5.6 \\
\hline Doing laundry** & 6 & 3.2 & 7 & 2.1 & 8 & 5.8 & 5 & 13.9 \\
\hline $\begin{array}{l}\text { Doing } \\
\text { housework** }\end{array}$ & 9 & 4.7 & 15 & 4.5 & 15 & 10.7 & 5 & 13.9 \\
\hline $\begin{array}{l}\text { Going places in } \\
\text { community }\end{array}$ & 8 & 4.1 & 22 & 6.6 & 13 & 9.4 & 4 & 11.1 \\
\hline
\end{tabular}

Note. Chi-square values are as follows: preparing meals, $\underline{X}^{2}(3, \underline{N}=700)=7.86$, $\mathrm{p}<.049$; shopping, $\underline{X}^{2}(3, \underline{N}=703)=19.91, \underline{p}<.001$; managing money, $\underline{X}^{2}(3, \underline{N}=699)=1.70, \underline{p}<.637$, using the telephone, $\underline{X}^{2}(3, \underline{N}=705)=16.37, \underline{p}<.001$;

doing laundry, $\underline{X}^{2}(3, \underline{N}=699)=14.63, \underline{p}<.002$; and doing housework, $\underline{\mathrm{X}}^{2}(3, \underline{N}=701)=10.88, \underline{\mathrm{p}}<.012 ;$ and getting to places in the community, $\underline{\mathrm{X}}^{2}(3)=4.75, \underline{\mathrm{p}}<.191$.

${ }^{\mathrm{a}}$ The numbers and percentages in each age group responding "yes" to the question, "Because of a health problem, do you have difficulty with (the corresponding IADL)?"

${ }^{\mathrm{b}}$ Sample sizes insufficient for chi-square comparisons.

$* * \mathrm{p}<.01$. 
examined separately and the results are presented in Table 14. Comparisons of the levels of difficulties with ADLs were based on a subset of the entire sample which contained only those respondents who reported difficulty with the specified ADL. In the survey, level of difficulty was scored on a three-point scale of "some", "a lot", or "completely unable to perform the task without assistance or special equipment".

For all ADLs in all age groups, the most frequently reported level of difficulty was the lowest one, "some". However, the severity of difficulty with the ADLs tended to increase with age. The greatest percentages of respondents who reported being unable to perform an ADL without assistance or special equipment were in the oldest age group ( $85+$ years).

Because only three ADLs (bathing, using stairs, and walking) contained sufficient sample sizes for chi-square comparisons across the four age groups, statistical analyses were performed in two ways, first, by comparing the four age groups and second, by collapsing the samples into two age groups, those 60 to 74 years and those 75 years and older. Bathing, using stairs, and walking were examined in the first method. Dressing, caring for appearance, toileting, and getting in and out of a chair were examined by the second method of collapsing age groups. Eating contained too few respondents in the "unable" category to permit either form of chi-square analysis. 
Table 14

Level of Difficulties with ADLs by Age Group

\begin{tabular}{|c|c|c|c|c|c|c|c|c|}
\hline \multirow[b]{3}{*}{ Level of Difficulty } & \multicolumn{8}{|c|}{ Age Group } \\
\hline & \multicolumn{2}{|c|}{$60-64$ yrs } & \multicolumn{2}{|c|}{$65-74$ yrs } & \multicolumn{2}{|c|}{$75-84$ yrs } & \multicolumn{2}{|c|}{$85+$ yrs } \\
\hline & $\underline{\mathrm{n}}$ & $\%$ & $\underline{\mathrm{n}}$ & $\%$ & $\underline{n}$ & $\%$ & $\underline{\mathrm{n}}$ & $\%$ \\
\hline \multicolumn{9}{|l|}{ Difficulty with } \\
\hline \multicolumn{9}{|l|}{ Bathing } \\
\hline Some difficulty & 11 & 73.3 & 38 & 61.3 & 25 & 51.0 & 16 & 41.0 \\
\hline A lot of difficulty & 2 & 13.3 & 16 & 25.8 & 15 & 30.6 & 11 & 28.2 \\
\hline Completely unable & 2 & 13.3 & 8 & 12.9 & 9 & 18.4 & 12 & 30.8 \\
\hline \multicolumn{9}{|c|}{ Difficulty with Using Stairs } \\
\hline Some difficulty & 48 & 58.5 & 87 & 55.1 & 70 & 61.4 & 30 & 50.0 \\
\hline A lot of difficulty & 20 & 24.4 & 49 & 31.0 & 28 & 24.6 & 12 & 20.0 \\
\hline Completely unable & 14 & 17.1 & 22 & 13.9 & 16 & 14.0 & 18 & 30.0 \\
\hline \multicolumn{9}{|l|}{ Difficulty with Walking } \\
\hline Some difficulty & 49 & 71.0 & 93 & 65.0 & 86 & 67.7 & 35 & 57.4 \\
\hline A lot of difficulty & 18 & 26.1 & 45 & 31.5 & 34 & 26.8 & 20 & 32.8 \\
\hline Completely unable & 2 & 2.9 & 5 & 3.5 & 7 & 5.5 & 6 & 9.8 \\
\hline
\end{tabular}

Difficulty with Dressing*

Some difficulty $\quad 20$

$\begin{array}{lll}83.3 & 24 & 61.5\end{array}$

$14 \quad 56.0$

$13 \quad 59.1$

A lot of difficulty $\quad 3 \quad 12.5$

$10 \quad 25.6$

$5 \quad 20.0$

$2 \quad 9.1$

Completely unable

4.2

$5 \quad 12.8$

$6 \quad 24.0$

$\begin{array}{ll}7 & 31.8\end{array}$

Difficulty with Eating ${ }^{\mathrm{b}}$

Some difficulty

A lot of difficulty

Completely unable

$7 \quad 53$

$\begin{array}{ll}6 & 46.2\end{array}$

$0 \quad 0.0$
$18 \quad 72.0$

$6 \quad 24.0$

14.0

$\begin{array}{rrrr}14 & 77.8 & 4 & 50.0 \\ 3 & 16.7 & 2 & 25.0 \\ 1 & 5.5 & 2 & 25.0\end{array}$

Difficulty with Taking Care of Appearance

$\begin{array}{lrrrrrrrr}\text { Some difficulty } & 5 & 62.5 & 14 & 60.9 & 12 & 75.0 & 10 & 50.0 \\ \text { A lot of difficulty } & 3 & 37.5 & 6 & 26.1 & 1 & 6.3 & 5 & 25.0 \\ \text { Completely unable } & 0 & 0.0 & 3 & 13.0 & 3 & 18.8 & 5 & 25.0\end{array}$

Difficulty with Toileting

Some difficulty

$\begin{array}{ll}5 & 41.7\end{array}$

$\begin{array}{ll}18 & 72.0\end{array}$

$12 \quad 75.0$

$\begin{array}{ll}7 & 53.8\end{array}$

A lot of difficulty

41.7

$5 \quad 20.0$

16.3

$\begin{array}{ll}3 & 23.1\end{array}$

Completely unable

16.7

28.0

$3 \quad 18.8$

(table continues) 
Table 14 (continued)

Level of Difficulties with ADLs by Age Group

Age Group

\begin{tabular}{|c|c|c|c|c|c|c|c|c|}
\hline \multirow[b]{3}{*}{ Level of Difficulty } & \\
\hline & \multicolumn{2}{|c|}{$60-64$ yrs } & \multicolumn{2}{|c|}{$65-74$ yrs } & \multicolumn{2}{|c|}{$75-84$ yrs } & \multicolumn{2}{|c|}{$85+$ yrs } \\
\hline & $\underline{\mathrm{n}}$ & $\%$ & $\underline{\mathrm{n}}$ & $\%$ & $\underline{n}$ & $\%$ & $\underline{\mathrm{n}}$ & $\%$ \\
\hline \multicolumn{9}{|c|}{ Difficulty with Getting in/out of a chair } \\
\hline Some difficulty & 35 & 70.0 & 84 & 80.8 & 54 & 77.1 & 23 & 60.5 \\
\hline A lot of difficulty & 12 & 24.0 & 17 & 16.3 & 10 & 14.3 & 10 & 26.3 \\
\hline Completely unable & 3 & 6.0 & 3 & 2.9 & 6 & 8.6 & 5 & 13.2 \\
\hline
\end{tabular}

Note. Values are based on respondents reporting difficulty with the corresponding ADL. Chi-square values are as follows: bathing, $\underline{X}^{2}(3, \underline{N}=165)=$ $8.61, \underline{p}<.197$, using stairs, $\underline{X}^{2}(3, \underline{N}=414)=11.00, \underline{p}<.089 ;$ walking, $\underline{X}^{2}(3, \underline{N}=400)$ $=6.21, \underline{p}<.40$; dressing, $\underline{X}^{2}(2, \underline{N}=110)=6.25, \underline{p}<.044$; taking care of appearance, $\underline{X}^{2}(2, \underline{N}=67)=2.73, \underline{p}<.255$; toileting, $\underline{X}^{2}(2, \underline{N}=66)=2.42, \underline{p}<.298$; and getting in and out of a chair, $\underline{X}^{2}(2, \underline{N}=262)=4.18, \underline{p}<.124$.

${ }^{\mathrm{b}}$ Sample sizes insufficient for chi-square comparisons. ${ }^{*} \mathrm{p}<.05$. 
In the first analysis, which examined bathing, using stairs, and walking, there were no significant differences in the level of difficulties across the four age groups (see Table 14). However, for each of these ADLs, the oldest age group contained almost twice as many respondents reporting being unable to perform the ADL in comparison to the younger age groups.

In the second analysis (collapsed age groups), there were no significant differences in the level of difficulties across the four age groups for caring for appearance, toileting, and getting in and out of a chair (see Table 14). However, for dressing, the difference across the two age groups was significant, $p<.044$. Twenty-eight percent of respondents 75 years and older reported being completely unable to dress independently, in comparison to $9.5 \%$ of respondents 60 to 74 years of age.

Level of difficulties with ADLs in the age groups by gender. Comparisons between age and level of difficulties with ADLs by gender produced no statistically meaningful results because of small sample sizes, even after collapsing the samples into two age groups ( $60-74$ years and $75+$ years).

Level of difficulties with IADLs in the four age groups. Each IADL was examined separately and the results are presented in Table 15. Comparisons of the levels of difficulties with IADLs were based on a subset of the entire sample which contained only those respondents who reported difficulty with the specified IADL. In the survey, level of difficulty was scored on a three-point scale of 
"some", "a lot" or "completely unable to perform the task without assistance or special equipment". For each IADL, the level of difficulty of respondents reporting difficulty was compared among the age groups.

Two IADLs, taking medicine and using the telephone, contained insufficient sample sizes for chi-square comparisons. Of the remaining six IADLs (preparing meals, shopping, managing money, doing laundry, doing housework, getting to places in the community), there were significant differences in the distribution of the levels of difficulties across the age groups (see Table 15).

As seen in Table 15, the majority of respondents in the youngest age group, 60 to 64 years, rated their difficulty as "some", whereas the respondents in the oldest group, ages 85 years and older, tended to rate their difficulty as "completely unable to perform the IADL without assistance or special equipment".

Level of difficulties with IADLs in the age groups by gender. Comparisons between age and level of difficulties with IADLs by gender produced no statistically meaningful results because of small sample sizes, even after collapsing the samples into two age groups ( 60 to 74 years and 75 years and older).

Number of ADLs with difficulties in the four age groups. The total number of ADLs (0-8) each respondent reported difficulty with was determined for each age group and the frequency distributions are presented in Table 16. 
Table 15

Level of Difficulties with IADLs by Age Group

\begin{tabular}{|c|c|c|c|c|c|c|c|c|}
\hline \multirow[b]{3}{*}{ Level of Difficulty } & \multicolumn{8}{|c|}{ Age Group } \\
\hline & \multicolumn{2}{|c|}{$60-64$ yrs } & \multicolumn{2}{|c|}{$65-74$ yrs } & \multicolumn{2}{|c|}{$75-84$ yrs } & \multicolumn{2}{|c|}{$85+y r s$} \\
\hline & $\underline{\mathrm{n}}$ & $\%$ & $\underline{\mathrm{n}}$ & $\%$ & $\underline{\mathrm{n}}$ & $\%$ & $\underline{\mathrm{n}}$ & $\%$ \\
\hline \multicolumn{9}{|c|}{ Difficulty with Preparing Meals* } \\
\hline Some difficulty & 13 & 61.9 & 13 & 33.3 & 15 & 45.5 & 13 & 40.6 \\
\hline A lot of difficulty & 3 & 14.3 & 17 & 43.6 & 8 & 24.2 & 4 & 12.5 \\
\hline Completely unable & 5 & 23.8 & 9 & 23.1 & 10 & 30.3 & 15 & 46.9 \\
\hline \multicolumn{9}{|c|}{ Difficulty with Shopping** } \\
\hline Some difficulty & 18 & 58.1 & 29 & 43.9 & 34 & 47.9 & 10 & 22.2 \\
\hline A lot of difficulty & 7 & 22.6 & 17 & 25.8 & 13 & 18.3 & 8 & 17.8 \\
\hline Completely unable & 6 & 19.4 & 20 & 30.3 & 24 & 33.8 & 27 & 60.0 \\
\hline
\end{tabular}

Difficulty with Managing Money**

$\begin{array}{lll}\text { Some difficulty } & 11 & 64.7\end{array}$

A lot of difficulty $\quad 4 \quad 23.5$

Completely unable $\quad 2 \quad 11.8$
$27 \quad 56.3$

$13 \quad 27.1$

$8 \quad 16.7$
1250.0

$2 \quad 8.3$

$\begin{array}{ll}10 & 41.7\end{array}$

$17 \quad 37.0$

$12 \quad 26.1$

$17 \quad 37.0$ $\begin{array}{ll}9 & 32.1\end{array}$

$5 \quad 17.9$

$14 \quad 50.0$ $\begin{array}{ll}6 & 22.2\end{array}$

$\begin{array}{ll}4 & 14.8\end{array}$

$17 \quad 63.0$

Difficulty with Doing Laundry**

$\begin{array}{lllllrrrr}\text { Some difficulty } & 9 & 60.0 & 17 & 37.0 & 9 & 32.1 & 7 & 20.0 \\ \text { A lot of difficulty } & 3 & 20.0 & 12 & 26.1 & 5 & 17.9 & 2 & 5.7 \\ \text { Completely unable } & 3 & 20.0 & 17 & 37.0 & 14 & 50.0 & 26 & 74.3\end{array}$

Difficulty with Doing Housework**

Some difficulty $\quad 25 \quad 54.3$

A lot of difficulty $\quad 15 \quad 32.6$

$\begin{array}{ll}42 & 47.7\end{array}$

$\begin{array}{ll}41 & 59.4\end{array}$

$\begin{array}{ll}16 & 34.0\end{array}$

Completely unable $\quad 6 \quad 13.0$

$25 \quad 28.4$

$13 \quad 18.8$

$\begin{array}{ll}6 & 12.8\end{array}$

$21 \quad 23.9$

$15 \quad 21.7$

$25 \quad 53.2$

Difficulty with Getting to Places in the Community*

$\begin{array}{lrrrrrrrr}\text { Some difficulty } & 13 & 44.8 & 43 & 46.2 & 32 & 50.0 & 15 & 34.9 \\ \text { A lot of difficulty } & 9 & 31.0 & 33 & 35.5 & 12 & 18.8 & 9 & 20.9 \\ \text { Completely unable } & 7 & 24.1 & 17 & 18.3 & 20 & 31.3 & 19 & 44.2\end{array}$

Difficulty with Taking Medicine

\begin{tabular}{llllllrrr} 
Some difficulty & 3 & 50.0 & 4 & 50.0 & 7 & 87.5 & 4 & 44.4 \\
A lot of difficulty & 2 & 33.3 & 2 & 25.0 & 0 & 0.0 & 3 & 33.3 \\
Completely unable & 1 & 16.7 & 2 & 25.0 & 1 & 12.5 & 2 & 22.2 \\
\hline
\end{tabular}


Table 15 (continued)

Level of Difficulties with IADLs by Age Group

\begin{tabular}{|c|c|c|c|c|c|c|c|c|}
\hline \multirow[b]{3}{*}{ Level of Difficulty } & \multicolumn{8}{|c|}{ Age Group } \\
\hline & \multicolumn{2}{|c|}{$60-64$ yrs } & \multicolumn{2}{|c|}{$65-74$ yrs } & \multicolumn{2}{|c|}{$75-84$ yrs } & \multicolumn{2}{|c|}{$85+$ yrs } \\
\hline & $\underline{n}$ & $\%$ & $\underline{n}$ & $\%$ & $\underline{n}$ & $\%$ & $\underline{n}$ & $\%$ \\
\hline \multicolumn{9}{|c|}{ Difficulty with Using Telephone } \\
\hline Some difficulty & 4 & 80.0 & 8 & 57.1 & 12 & 52.2 & 5 & 23.8 \\
\hline A lot of difficulty & 0 & 0.0 & 5 & 357 & 7 & 30.4 & 5 & 23.8 \\
\hline Completely unable & 1 & 20.0 & 1 & 7.1 & 4 & 17.4 & 11 & 52.4 \\
\hline
\end{tabular}

Note. Values are based on respondents reporting difficulty with the corresponding ADL. Chi-square values are as follows: preparing meals, $\underline{X}^{2}(6$, $\underline{N}=125)=14.54, \underline{p}<.024$, shopping, $\underline{X}^{2}(6, \underline{N}=213)=18.04, \underline{p}<.006$, managing money, $\underline{X}^{2}(6, \underline{N}=116)=23.27, \underline{p}<.001$, doing laundry, $\underline{X}^{2}(6, \underline{N}=124)=18.48, \underline{p}<$ .005 , doing housework, $\underline{X}^{2}(6, \underline{N}=250)=25.76, \underline{p}<.001$, and getting to places in the community, $\underline{X}^{2}(6, \underline{N}=229)=13.78, \underline{p}<.032$.

${ }^{*} \mathrm{p}<.05,{ }^{* *} \mathrm{p}<.01$ 
Table 16

Number of Difficulties with ADLs by Age Group

\begin{tabular}{|c|c|c|c|c|c|c|c|c|}
\hline \multirow[b]{3}{*}{$\begin{array}{l}\text { No. of ADLs with } \\
\text { difficulty }\end{array}$} & \multicolumn{8}{|c|}{ Age Group } \\
\hline & \multicolumn{2}{|c|}{$60-64$ yrs } & \multicolumn{2}{|c|}{$65-74$ yrs } & \multicolumn{2}{|c|}{$75-84$ yrs } & \multicolumn{2}{|c|}{$85+$ yrs } \\
\hline & $\underline{\mathrm{n}}$ & $\%$ & $\underline{\mathrm{n}}$ & $\%$ & $\underline{\mathrm{n}}$ & $\%$ & $\underline{\mathrm{n}}$ & $\%$ \\
\hline 1 & 45 & 38.5 & 106 & 41.9 & 63 & 33.9 & 23 & 26.7 \\
\hline 2 & 36 & 30.8 & 60 & 23.7 & 52 & 28.0 & 22 & 25.6 \\
\hline 3 & 14 & 12.0 & 42 & 16.6 & 42 & 22.6 & 12 & 14.0 \\
\hline $4-8$ & 22 & 18.8 & 45 & 17.8 & 29 & 15.6 & 29 & 33.7 \\
\hline Total & 117 & 100.0 & 253 & 100.0 & 186 & 100.0 & 86 & 100.0 \\
\hline
\end{tabular}

Note. $\underline{X}^{2}(9, \underline{N}=642)=22.77, \underline{p}<.007$ 
Comparisons were based on those individuals in each age group who reported at least one difficulty with an ADL.

The distributions of the number of ADLs the person had difficulty with were significantly different across the four age groups, $\mathfrak{p}<.007$. The percentage of respondents reporting difficulties with four to eight ADLs was highest among those 85 years and older $(33.7 \%)$.

Number of ADLs with difficulties in the four age groups by gender. For both males and females, the percentage of respondents reporting difficulty with four to eight ADLs was highest in individuals 85 years and older $(25 \%$ for males and $35.7 \%$ for females) (see Table 17). For females, the distributions of the number of ADLs with difficulty among the four age groups were significantly different, $\mathrm{p}<.023$. However, for males the distributions were not significantly different, $\mathrm{p}<.795$. 
Table 17

Number of Difficulties with ADLs by Age Group and Gender

Females

\begin{tabular}{|c|c|c|c|c|c|c|c|c|}
\hline \multirow[b]{3}{*}{$\begin{array}{l}\text { No. of ADLs with } \\
\text { difficulty }\end{array}$} & \multicolumn{8}{|c|}{ Age Group } \\
\hline & \multicolumn{2}{|c|}{$60-64$ yrs } & \multicolumn{2}{|c|}{$65-74$ yrs } & \multicolumn{2}{|c|}{$75-84$ yrs } & \multicolumn{2}{|c|}{$85+y r s$} \\
\hline & $\underline{\mathrm{n}}$ & $\%$ & $\underline{\mathrm{n}}$ & $\%$ & $\underline{\mathrm{n}}$ & $\%$ & $\underline{\mathrm{n}}$ & $\%$ \\
\hline 1 & 25 & 33.8 & 77 & 41.2 & 45 & 31.7 & 18 & 25.7 \\
\hline 2 & 24 & 32.4 & 43 & 23.0 & 41 & 28.9 & 16 & 22.9 \\
\hline 3 & 10 & 13.5 & 31 & 16.6 & 33 & 23.2 & 11 & 15.7 \\
\hline $4-8$ & 15 & 20.3 & 36 & 19.3 & 23 & 16.2 & 25 & 35.7 \\
\hline Total & 74 & 100.0 & 187 & 100.0 & 142 & 100.0 & 70 & 100.0 \\
\hline \multicolumn{9}{|c|}{ Note. $\underline{X}^{2}(9, \underline{N}=473)=19.27, \underline{p}<.023$} \\
\hline \multicolumn{9}{|l|}{ Males } \\
\hline & \multicolumn{8}{|c|}{ Age Group } \\
\hline & \multicolumn{2}{|c|}{$60-64$ yrs } & \multicolumn{2}{|c|}{$65-74$ yrs } & \multicolumn{2}{|c|}{$75-84$ yrs } & \multicolumn{2}{|c|}{$85+$ yrs } \\
\hline $\begin{array}{l}\text { No. of ADLs with } \\
\text { difficulty }\end{array}$ & $\underline{\mathrm{n}}$ & $\%$ & $\underline{\mathrm{n}}$ & $\%$ & $\underline{\mathrm{n}}$ & $\%$ & $\underline{\mathrm{n}}$ & $\%$ \\
\hline 1 & 20 & 46.5 & 29 & 43.9 & 18 & 40.9 & 5 & 31.3 \\
\hline 2 & 12 & 27.9 & 17 & 25.8 & 11 & 25.0 & 6 & 37.5 \\
\hline 3 & 4 & 9.3 & 11 & 16.7 & 9 & 20.5 & 1 & 6.3 \\
\hline $4-8$ & 7 & 16.3 & 9 & 13.6 & 6 & 13.6 & 4 & 25.0 \\
\hline Total & 43 & 100.0 & 66 & 100.0 & 44 & 100.0 & 16 & 100.0 \\
\hline
\end{tabular}


number of IADLs each respondent reported difficulty with was determined for each age group and the frequency distributions are presented in Table 18.

Comparisons were based on those individuals in each age group who reported at least one difficulty with an IADL.

The distributions of the number of IADLs with difficulty were significantly different among the four age groups, $\mathrm{p}<.001$. Approximately $50 \%$ of respondents in the three youngest age groups reported having difficulty with only one IADL as compared to $18.5 \%$ in the oldest group, 85 years and older. The percentage of respondents reporting difficulties with four to eight IADLs was highest among those 85 years and older $(50.8 \%)$ and was more than double the percentages in the other age groups $(17.1 \%$ in 60 to 64 years, $24.9 \%$ in 65 to 74 years, and $18.7 \%$ in 75 to 84 years).

Number of IADLs with difficulties in the four age groups by gender. As seen with ADLs, the percentage of respondents reporting difficulty with four to eight IADLs for both males and females was highest in individuals 85 years and older $(57.1 \%$ for males and $50.0 \%$ for females) (see Table 19). As was the case with ADLs, the distributions of the number of IADLs performed with difficulty among the four age groups were significantly different for females, $\underline{\mathrm{p}}<.001$, but not significantly different for males, $\underline{p}<.193$. 
Table 18

Number of Difficulties with IADLs by Age Group

\begin{tabular}{|c|c|c|c|c|c|c|c|c|}
\hline \multirow[b]{3}{*}{$\begin{array}{l}\text { No. of IADLs } \\
\text { with difficulty }\end{array}$} & \multicolumn{8}{|c|}{ Age Group } \\
\hline & \multicolumn{2}{|c|}{$60-64$ yrs } & \multicolumn{2}{|c|}{$65-74$ yrs } & \multicolumn{2}{|c|}{$75-84$ yrs } & \multicolumn{2}{|c|}{$85+$ yrs } \\
\hline & $\underline{n}$ & $\%$ & $\underline{\mathrm{n}}$ & $\%$ & $\underline{\mathrm{n}}$ & $\%$ & $\underline{\mathrm{n}}$ & $\%$ \\
\hline 1 & 41 & 50.0 & 95 & 52.5 & 69 & 49.6 & 12 & 18.5 \\
\hline 2 & 17 & 20.7 & 29 & 16.0 & 22 & 15.8 & 12 & 18.5 \\
\hline 3 & 10 & 12.2 & 12 & 6.6 & 22 & 15.8 & 8 & 12.3 \\
\hline $4-8$ & 14 & 17.1 & 45 & 24.9 & 26 & 18.7 & 33 & 50.8 \\
\hline Total & 82 & 100.0 & 181 & 100.0 & 139 & 100.0 & 65 & 100.0 \\
\hline
\end{tabular}

Note. $\underline{X}^{2}(9, \underline{N}=467)=41.36, \underline{p}<.001$ 
Table 19

Number of Difficulties with IADLs by Age Group and Gender

Females

Age Group

\begin{tabular}{|c|c|c|c|c|c|c|c|c|}
\hline \multirow[b]{2}{*}{$\begin{array}{l}\text { No. of IADLs } \\
\text { with difficulty }\end{array}$} & \multicolumn{2}{|c|}{$60-64$ yrs } & \multicolumn{2}{|c|}{$65-74$ yrs } & \multicolumn{2}{|c|}{$75-84$ yrs } & \multicolumn{2}{|c|}{$85+$ yrs } \\
\hline & $\underline{n}$ & $\%$ & $\underline{\mathrm{n}}$ & $\%$ & $\underline{n}$ & $\%$ & $\underline{\mathrm{n}}$ & $\%$ \\
\hline 1 & 25 & 44.6 & 62 & 45.9 & 52 & 48.1 & 10 & 17.2 \\
\hline 2 & 14 & 25.0 & 23 & 17.0 & 19 & 17.6 & 11 & 19.0 \\
\hline 3 & 8 & 14.3 & 11 & 8.1 & 18 & 16.7 & 8 & 13.8 \\
\hline $4-8$ & 9 & 16.1 & 39 & 28.9 & 19 & 17.6 & 29 & 50.0 \\
\hline Total & 56 & 100.0 & 135 & 100.0 & 108 & 100.0 & 58 & 100.0 \\
\hline
\end{tabular}

Males

\begin{tabular}{|c|c|c|c|c|c|c|c|c|}
\hline \multirow[b]{3}{*}{$\begin{array}{l}\text { No. of IADLs } \\
\text { with difficulty }\end{array}$} & \multicolumn{8}{|c|}{ Age Group } \\
\hline & \multicolumn{2}{|c|}{$60-64$ yrs } & \multicolumn{2}{|c|}{$65-74$ yrs } & \multicolumn{2}{|c|}{$75-84$ yrs } & \multicolumn{2}{|c|}{$85+$ yrs } \\
\hline & $\underline{n}$ & $\%$ & $\underline{n}$ & $\%$ & $\underline{n}$ & $\%$ & $\underline{n}$ & $\%$ \\
\hline 1 & 16 & 61.5 & 33 & 71.7 & 17 & 54.8 & 2 & 28.6 \\
\hline 2 & 3 & 11.5 & 6 & 13.0 & 3 & 9.7 & 1 & 14.3 \\
\hline 3 & 2 & 7.7 & 1 & 2.2 & 4 & 12.9 & 0 & 0.0 \\
\hline $4-8$ & 5 & 19.2 & 6 & 13.0 & 7 & 22.6 & 4 & 57.1 \\
\hline Total & 26 & 100.0 & 46 & 100.0 & 31 & 100.0 & 7 & 100.0 \\
\hline
\end{tabular}


Mean number of ADLs with difficulties in the four age groups. The mean

number of ADLs respondents reported difficulty with was determined for each age group and the means and standard deviations are presented in Table 20. Comparisons were based only on those individuals in each age group who reported difficulty with one or more ADLs.

The oldest age group, ages 85 years and older, had the highest average number of difficulties with ADLs $(\underline{\mathrm{M}}=3.07)$ and the difference among age groups was significant, $\underline{\mathrm{F}}(3,638)=4.88, \underline{\mathrm{p}}<.001$. Bonferroni's post hoc tests revealed that the oldest age group was significantly different than the other groups (see Table 20). However, comparisons between pairs of the three youngest age groups revealed no significant differences between the mean number of difficulties with ADLs.

Mean number of ADLs with difficulties in the four age groups by gender. For both males and females, the average number of ADLs with difficulty was highest in the oldest age group (for males, $\underline{M}=2.56$ and for females, $\underline{M}=3.19$ ) (see Table 20). For males, there were no significant differences among age groups, $\underline{F}(3,165)=.30, \underline{p}<.827$. However, for females, there were significant differences in the average number of ADLs with difficulty among age groups, $\underline{F}(3,469)=12.38, \underline{p}<.005$. Bonferroni's post hoc tests revealed that the oldest age group was significantly different than the other groups. Comparisons between pairs of the three youngest age groups revealed no significant differences between the mean number of difficulties with ADLs among females. 
Table 20

Mean Number of Difficulties with ADLs by Age Group

\begin{tabular}{|c|c|c|c|c|}
\hline \multirow[b]{2}{*}{$\begin{array}{l}\text { Difficulties } \\
\text { with ADLs }\end{array}$} & \multicolumn{4}{|c|}{ Age Group } \\
\hline & $60-64$ yrs & $65-74$ yrs & $75-84$ yrs & $85+$ yrs \\
\hline \multicolumn{5}{|l|}{ Total** } \\
\hline$\underline{\mathrm{n}}$ & 117 & 253 & 186 & 86 \\
\hline$\overline{\mathrm{M}}$ & 2.34 & 2.31 & 2.38 & 3.07 \\
\hline$\underline{\mathrm{SD}}$ & 1.61 & 1.63 & 1.50 & 2.05 \\
\hline
\end{tabular}

Females**

$\begin{array}{rrrrr}\underline{\mathrm{n}} & 74 & 187 & 142 & 70 \\ \underline{\mathrm{M}} & 2.43 & 2.36 & 2.44 & 3.19 \\ \underline{\mathrm{SD}} & 1.61 & 1.68 & 1.52 & 2.09\end{array}$

Males

$\begin{array}{rrrrr}\underline{\mathrm{n}} & 43 & 66 & 44 & 16 \\ \underline{\mathrm{M}} & 2.19 & 2.17 & 2.20 & 2.56 \\ \underline{\mathrm{SD}} & 1.64 & 1.50 & 1.41 & 1.82\end{array}$

Note. Results of ANOVA tests are as follows: for the total sample,

$\underline{F}(3,638)=4.88, \underline{p}<.001$, for females, $\underline{F}(3,469)=12.38, \underline{p}<.005$, and for males, $\underline{\mathrm{F}}(3,165)=.30, \mathrm{p}<.827$.

$* * \mathrm{p}<.01$ 
Mean number of IADLs with difficulties in the four age groups. The mean number of IADLs respondents reported difficulty with was determined for each age group and the means and standard deviations are presented in Table 21. Comparisons were based only on those individuals in each age group who reported difficulty with one or more IADLs.

The difference in the average number of IADLs with difficulties was significant among age groups, $\underline{\mathrm{F}}(3,463)=19.10, \underline{\mathrm{p}}<.001$.

Bonferroni's post hoc tests revealed a similar pattern as seen in difficulties with ADLs. The oldest age group ( $85+$ years) was significantly higher $(\underline{M}=4.03)$ than the other age groups and the three youngest groups were not significantly different from one another.

Mean number of IADLs with difficulties in the four age groups by gender. For both males and females, the average number of IADLs with difficulty was highest in the oldest age group ( $\underline{M}=3.86$ for males and $\underline{M}=4.05$ for females) (see Table 21). In addition, for both genders, the difference between age groups was significant $(\underline{F}(3,106)=4.0, \underline{p}<.01$ for males and $\underline{F}(3,353)=15.02, \underline{p}<.001$ for females). Bonferroni post hoc comparisons revealed that for females, there was a significant difference between the oldest age group and the other three groups. The differences between the three youngest groups were not significant for females. For males, Bonferroni post hoc comparisons revealed only one significant difference between groups 65 to 74 years and 85 years and older. 
Table 21

Mean Number of Difficulties with IADLs by Age Group

Age Group

\begin{tabular}{|c|c|c|c|c|}
\hline $\begin{array}{l}\text { Difficulties } \\
\text { with IADLs }\end{array}$ & $60-64$ yrs & $65-74$ ys & $75-84$ yrs & $85+$ yrs \\
\hline Total** & & & & \\
\hline$\underline{\mathrm{n}}$ & 82 & 181 & 139 & 65 \\
\hline$\underline{\bar{M}}$ & 2.10 & 2.25 & 2.31 & 4.03 \\
\hline $\mathrm{SD}$ & 1.45 & 1.68 & 1.76 & 2.38 \\
\hline
\end{tabular}

Females**

$\begin{array}{rrrrr}\underline{\mathrm{n}} & 56 & 135 & 108 & 58 \\ \underline{\mathrm{M}} & 2.14 & 2.45 & 2.29 & 4.05 \\ \underline{\mathrm{SD}} & 1.41 & 1.74 & 1.71 & 2.39\end{array}$

Males**

$\begin{array}{rrrrr}\underline{\mathrm{n}} & 26 & 46 & 31 & 7 \\ \underline{\mathrm{M}} & 2.00 & 1.67 & 2.39 & 3.86 \\ \underline{\mathrm{SD}} & 1.57 & 1.32 & 1.93 & 2.54\end{array}$

Note. Results of ANOVA tests are as follows: for the total sample,

$\underline{F}(3,463)=19.10, \underline{p}<.001$, for females, $\underline{F}(3,353)=15.02, \underline{p}<.001$, and for males, $\underline{\mathrm{F}}(3,106)=4.0, \underline{\mathrm{p}}<.01$.

$* * \underline{p}<.01$ 
$\underline{\text { Research questions three and four: Is there a relationship between self-reported }}$ health and self-reported functional ability of the elderly? Does the relationship between self-reported health and self-reported functional ability differ among four age groups of elderly individuals?

Correlations between self-reported health and difficulties with ADLs in the four age groups. The relationships between self-reported health and number of difficulties with ADLs for each of the four age groups were examined using Pearson correlation coefficients (see Table 22). There were positive correlations between the two variables in all four age groups. As the number of difficulties with ADLs increased, self-reported health became poorer $(4=$ poor health and $1=$ excellent health). The correlations ranged from $\underline{r}=.463$ in ages 60 to 64 years to $\underline{r}=.310$ in ages 85 years and older. For each age group, the correlations between self-reported health and difficulties with ADLs were significant, $\mathrm{ps}<.01$ (see Table 36).

An overall z-test revealed that the relationship between self-reported health and difficulties with ADLs weakened with age, $\underline{X}^{2}(3, \underline{N}=1952)=11.83, \underline{p}$ $<.008$. However, results of pairwise $z$-tests revealed that the differences between the correlations were significant between some but not all age groups. The correlation for ages 75 to 84 years $(\underline{r}=.324)$ was significantly lower than from that for ages 60 to 64 years $(\underline{r}=.463)$ and ages 65 to 74 years $(\underline{r}=.462), \underline{p}<.01$. 
Table 22

Correlations between Self-Reported Health and Mean Number of Difficulties with ADLs by Age Group

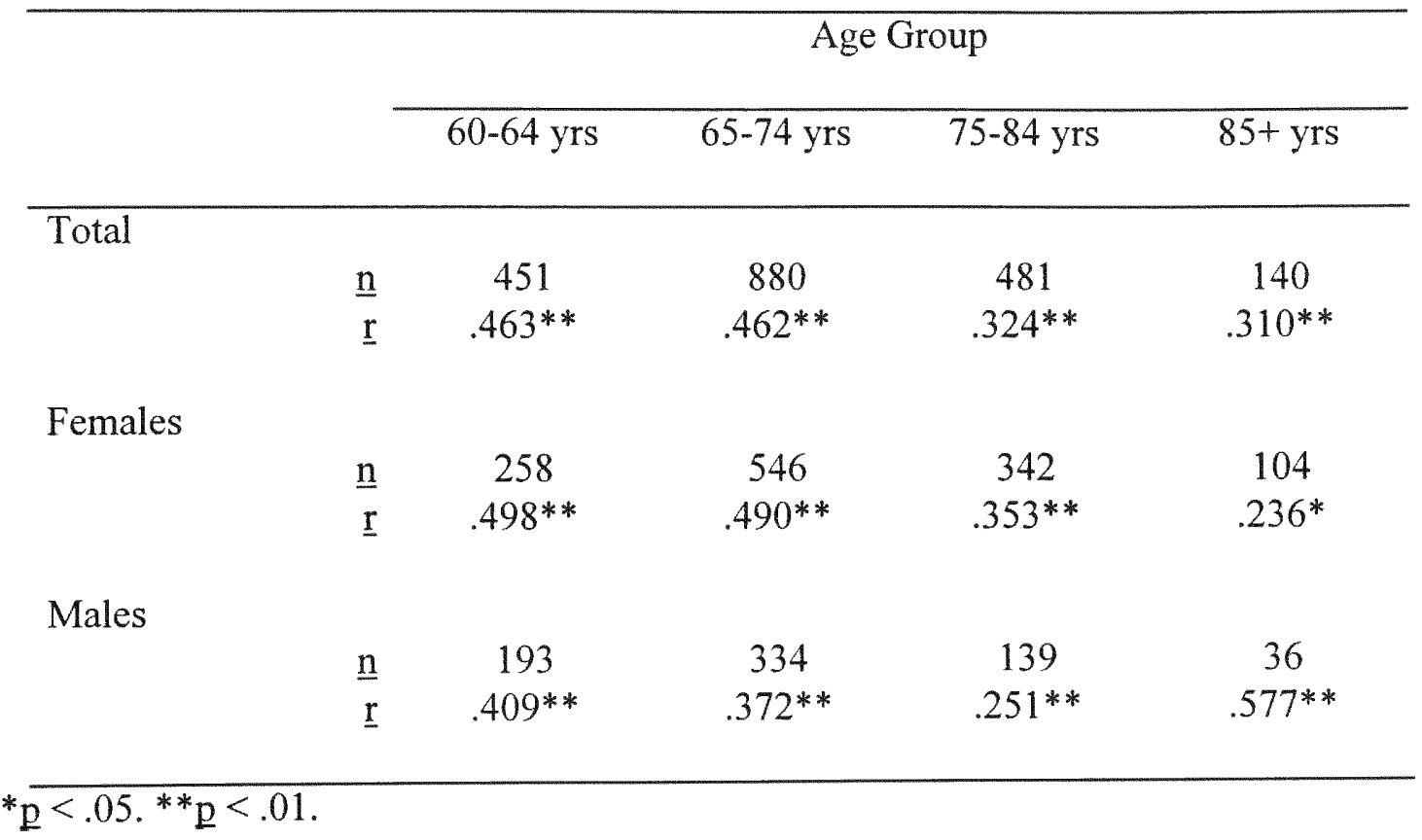


The correlation for ages 85 years and older $(\underline{r}=.310)$ was not significantly different from the other age groups.

Correlations between self-reported health and difficulties with ADLs in the four age groups by gender. The correlations between self-reported health and difficulties with ADLs differed among the age groups for both males and females.

Among females the correlations decreased with age from $r=.498$ in ages 60 to 64 years to $r=.236$ in ages 85 years and older and they were all positive correlations, $\mathrm{ps}<.01$. An overall z-test of the correlations for females revealed that the relationship between self-reported health and difficulties with ADLs weakened with age, $\underline{X}^{2}(3, \underline{N}=1250)=12.65, \underline{p}<.005$. Pairwise $z$-tests revealed there were significant differences in the correlations between the youngest age group ( 60 to 64 years) and ages 75 to 84 years and ages 85 years and older, but there was no significant difference between the youngest group and ages 65 to 74 years. Likewise, there were significant differences in correlations between the oldest age group, 85 years and older, and ages 60 to 64 years and ages 65 to 74 years, but no significant difference between the oldest group and ages 75 to 84 years. 
Table 23

Correlations between Self-Reported Health and Mean Number of Difficulties with

IADLs by Age Group

\begin{tabular}{|c|c|c|c|c|c|}
\hline & & \multicolumn{4}{|c|}{ Age Group } \\
\hline & & 60-64 years & $65-74$ years & $75-84$ years & $85+$ years \\
\hline \multicolumn{6}{|l|}{ Total } \\
\hline & $\underline{\mathrm{n}}$ & 451 & 880 & 481 & 140 \\
\hline & $\underline{r}$ & $.326^{* *}$ & $.420 * *$ & $.249 * *$ & $.215^{*}$ \\
\hline \multicolumn{6}{|l|}{ Females } \\
\hline & $\underline{\mathrm{n}}$ & 258 & 546 & 342 & 104 \\
\hline & $\underline{r}$ & $.350 * *$ & $.447^{* *}$ & $.294 * *$ & .180 \\
\hline \multicolumn{6}{|l|}{ Males } \\
\hline & $\underline{\mathrm{n}}$ & 193 & 334 & 139 & 36 \\
\hline & $\underline{r}$ & $.287^{* * *}$ & $.329 * *$ & .136 & $.357^{*}$ \\
\hline
\end{tabular}


Among males, the correlations between self-reported health and difficulties with ADLs in the four age groups were also significant and positive, $\mathrm{p}<.01$. However, an overall z-test revealed that there were no significant differences among the correlations across age groups among males, $\underline{X}^{2}(3, \underline{N}=702)$ $=5.17, \mathrm{p}<.160$.

Correlations between self-reported health and difficulties with IADLs in the four age groups. The relationships of self-reported health and number of difficulties with IADLs for each of the four age groups were examined by Pearson correlation coefficients (see Table 23). The comparisons revealed that there were positive and significant correlations for all age groups, $\mathrm{ps}<.01$. The correlations were lowest in the two oldest age groups ( $\underline{r}=.249$ and $\underline{r}=.215)$.

An overall z-test revealed that the relationship between self-reported health and difficulties with IADLs was significantly different across age groups, $\underline{X}^{2}(3, \underline{N}=1952)=15.03, \underline{p}<.002$. Pairwise $z$-tests revealed that the differences between the correlations were significant between some but not all age groups. The correlation for the age group 65 to 74 years $(\underline{r}=.324)$ was significantly higher than age group 75 to 84 years $(\underline{r}=.249)$ and age group 85 years and older $(\underline{r}=.215), \mathrm{ps}<.01$. No other significant differences were found. 
the four age groups by gender. Among females and males, the correlations between self-reported health and difficulties with IADLs were direct correlations, however in some age groups the correlations were not significant (see Table 23).

For females, the correlations between self-reported health and difficulties with IADLs were significant in the three youngest age groups, $\mathrm{ps}<.01$. The oldest age group had the lowest correlation $(\underline{r}=.180)$ and was not significant, $\mathrm{p}>$.05. An overall z-test for females revealed that the relationship between selfreported health and difficulties with IADLs was significantly different across age groups, $\underline{X}^{2}(3, \underline{N}=1250)=11.54, \underline{p}<.009$. Pairwise $z$-tests revealed that the correlations for age group 75 to 84 years $(\underline{r}=.294)$ was significantly different from that for age group 65 to 74 years $(\underline{r}=.447)$ and age group 85 years and older $(r=180)$. No other significant differences between age groups in females were found.

For males, correlations were significant for age groups 60 to 64 years $(\underline{r}=.287), 65$ to 74 years $(\underline{r}=.329)$, and 85 years and older $(\underline{r}=.357), \underline{p s}<.05$. For age group 75 to 84 years, the correlation $(\underline{r}=.136)$ was not significant, $p>.05$. An overall z-test for males revealed that the relationships between self-reported health and difficulties with IADLs were not significantly different across age groups, $\underline{X}^{2}$ $(3, \underline{N}=702)=4.31, \underline{p}<.230$. 


\section{Summary of findings}

In summary, this study examined self-reported health ratings and selfreported difficulties with functional abilities (eight ADLs and eight IADLs) across four age groups of elderly individuals from Dade County, Florida.

The major findings of the study were:

(1) Self-reported health ratings were significantly different across age groups. All age groups reported relatively high frequencies of positive health, but ratings of "excellent" and "good" health decreased with age;

(2) Difficulties with self-reported functional abilities increased with age, but this increase was most dramatic in the oldest age group ( $85+$ years);

(3) There were significant and positive relationships between selfreported health and self-reported functional ability in the four age groups and as the number of difficulties with ADLs or IADLs increased, self-reported health became poorer;

(4) The relationship between self-reported health and self-reported functional ability weakened with age; and

(5) There were differences in the distributions of males and females in all of the comparisons of self-reported health and self-reported functional abilities across age groups. 


\section{CHAPTER V}

\section{DISCUSSION}

\section{$\underline{\text { Research questions }}$}

This study examined four research questions: (a) Is there a relationship between self-reported health and age of the elderly? (b) Is there a relationship between self-reported functional ability and age of the elderly? (c) Is there a relationship between self-reported health and self-reported functional ability of the elderly? (d) Does the relationship between self-reported health and selfreported functional ability differ among four age groups of elderly individuals? Demographics of the study

The study sample was taken from the Comprehensive Needs Assessment Survey of Elders 60 years and older living in Dade County which had been designed to be a representative sample of $0.5 \%$ of the total population of aged 60 years and older living in Dade County (Condon et al. 1994). In comparison to 1990 U.S. Census figures for Dade County, the study sample resembled the demographic profile of the population aged 60 years and older in Dade County. In this study, the sample was divided into four age groups: (a) 60 to 64 years, (b) 65 to 74 years, (c) 75 to 84 years, and (d) 85 years and older. The mean age of the sample was 71.5 years. Significant differences were found in gender, ethnicity, level of education and income across age groups. 
In all age groups, females outnumbered males, and the percentage of females increased with age. This finding is consistent with US Census data and reflects the fact that in the US women have longer life expectancies than men (US Bureau of Census, 1996).

Another difference across age groups was seen in the cultural/ethnic composition. The major ethnic groups represented in the study were White nonHispanic (44.7\%), Cuban (34.0\%), Black non-Hispanic (10.7\%), and non-Cuban Hispanic (9.4\%). Contrasting trends were seen in the ethnic groups. For example, the proportion of White non-Hispanics increased with age, while that of Black non-Hispanics decreased. This finding probably reflects the higher life expectancy of White non-Hispanics in comparison with other ethnic groups. The large percentage of White non-Hispanic respondents in the two oldest age groups $(51.1 \%$ and $54.6 \%)$ can also be explained by the fact that a substantial number of White non-Hispanics workers retire to South Florida. The percentage of Hispanic respondents remained relatively stable across the age groups, and comprised between $40 \%$ and $47 \%$ of the total sample. The high percentage of Hispanic respondents in all age groups is a reflection of the steady immigration of individuals, especially from Cuba and other Central American nations, since the 1950s.

There were significant differences in education across age groups. The level of education decreased with age. The percentage of college graduates was 
higher in the two younger age groups ( $28.2 \%$ and $23.2 \%$ ) than the older groups $(14.6 \%$ and $17.7 \%)$.

Level of income was also significantly different across age groups and decreased with age. Over $18 \%$ of respondents in the oldest age group ( 85 years and older) had an annual income of less than $\$ 5,000$, in comparison with $11 \%$ in the youngest group (60 to 64 years of age). The youngest group also had the highest percentage (10.6\%) of respondents with annual incomes over $\$ 70,000$. This probably is due in part to the fact that the oldest group has been retired from the workforce and living on a fixed income the longest of all the groups, and the youngest group is likely currently employed.

Research question one: Is there a relationship between self-reported health and age of the elderly?

The study found a relationship between self-reported health and age of the elderly. In this study, self-reported health was measured by the response to question 7 of the survey questionnaire, "Compared to others your age, how would you rate your overall health?" The respondents rated their health as being: "excellent", "good", "fair" or "poor". Results show that self-reported health ratings were significantly different across the four age groups and there was a gradual decrease in favorable health ratings with age. For all ages, at least $60 \%$ of the respondents rated their health as either "excellent" or "good", but this 
percentage decreased from $68.1 \%$ in the youngest group (60-64 years) to $60.7 \%$ in the oldest group ( $85+$ years).

These results support the findings of Borawski et al. (1996), Manderbacka et al. (1996), and others who have found that most elderly individuals rated their health relatively favorably, which suggests that feelings of poor health are not necessarily synonymous with old age. Even the oldest-old (85+ years) age group tended to report positive health ratings. However, the present study as well as others did find an increase in negative ratings of health with increasing age. Borawski et al. (1996) examined age differences in self-reported health in 885 individuals aged 73 to 98 years from three retirement communities in Florida and reported that $66.6 \%$ of respondents rated their health as "healthy" or "very healthy" (on a five-point scale of "very healthy", "healthy", "fairly healthy", "sick" and "very sick"). Nevertheless, they also found that respondents 85 years of age and older were more likely to report being "fairly healthy" or "sick" than those under 85 years of age. Borwaski et al. (1996) also compared the health ratings of respondents to mortality rates over a three year period and found that individuals who rated their health in positive terms despite having declines in physical functioning were less likely to die than those who had similar declines in functioning but rated their health as poor. As a part of their study, Borawski et al. (1996) asked respondents to explain the reasons behind their current state of health and discovered that, in comparison with the younger respondents, the older 
respondents in the sample more often attributed their health to psychological factors (e.g., "having a good attitude" or "not letting things bother me") as opposed to physical health factors (e.g., "have few or no symptoms" or "don't take medications"). The researchers suggested that maintaining a positive outlook of health throughout old age may serve a protective function with respect to mortality.

It must be noted that the present study was based on a culturally diverse sample with the majority of respondents representing four cultural/ethnic groups (White non-Hispanics, Black non-Hispanics, Cubans, and non-Cuban Hispanics). Unfortunately, the sample sizes of each cultural group were not sufficient to permit statistical comparisons across age groups by gender and culture. There may have been differences in self-reported health across age groups from the different cultural groups which were undetected in this study.

A recent study by Jylha et al. (1998) demonstrated that self-reported health may be affected by cultural affiliation of the individual. They compared gender and age differences in self-reported health in two different cultural groups of elders (one from Finland and the other from Italy). The researchers divided the study samples into two age groups (60-74 years and 75-89 years) and found that within each cultural group there were not significant differences in the health ratings between males and females in the two age groups. However, there were 
differences between the cultural groups. In both age groups and genders, respondents from Italy rated their health better than respondents from Finland.

Relationship in self-reported health and age by gender. In this study, examinations of self-reported health ratings in the two genders produced trends similar to those seen in the entire sample. In both males and females, there were significant differences in self-reported health across age groups and positive ratings of health declined with age.

These findings are consistent with others (e.g., Borwaski et al., 1996 and Jylha et al., 1998) who have reported similar trends across age groups in the health ratings of elderly males and females. Again, there may have been gender differences across age groups in the four major cultural groups represented in the study, but the study sample was not of sufficient size to permit statistical comparisons by both gender and cultural group across the four age groups. $\underline{\text { Research question two: Is there a relationship between self-reported functional }}$ ability and age of the elderly?

The results of the study found a relationship between self-reported functional ability and age of the elderly. There were significant differences across the four age groups in the presence of difficulties with ADLs and IADLs, the levels of difficulty, the number of difficulties, and the mean numbers of difficulties. This study also found gender differences in the age-related trends in functional abilities. 
In this study, self-reported functional ability was measured by the responses to a pair of questions regarding performance of eight ADLs and eight IADLs. The first question asked "Because of a health problem, do you have difficulty with (the specified ADL or IADL). If the respondent answered "yes", the respondent was asked to rate the level of difficulty on a three-point scale: (a) some difficulty, (b) a lot of difficulty, or (c) completely unable without assistance from people or special equipment. Evaluation of functional ability was then based on presence of difficulties, level of difficulty, numbers of difficulties, and the mean number of difficulties with ADLs and IADLs across age groups.

Presence of difficulties with ADLs and IADLs in the four age groups. For all ADLs and IADLs, the percentage of respondents reporting difficulty increased with age, and in most cases, these percentages more than tripled from the youngest to oldest age groups. However, this increase was most dramatic between age group 75 to 84 years and age group 85 years and older. For example, from youngest to oldest, the percentages of respondents reporting difficulty with appearance were $1.8 \%, 2.8 \%, 3.3$, and $15.1 \%$, respectively. Likewise, for difficulty with walking, which was one of the highest reported difficult ADLs, the percentages reporting difficulty were $15.2 \%, 16.3 \%, 26.7 \%$, and $44.3 \%$, respectively from youngest to oldest age group. The findings of age-related declines in functional abilities were similar to those from national surveys of elders (Manton et al., 1993; Weiner et al., 1990; US Bureau of Census, 1996). 
In this study, the ADL which had the least reported difficulty in all age groups was eating. In fact, difficulty with eating was not significantly different across age groups and ranged from $2.9 \%$ and $2.8 \%$ in the two youngest age groups to $3.7 \%$ and $5.7 \%$ in the two oldest groups. These results are consistent with national surveys (US Bureau of the Census, 1996). According to the US Bureau of Census (1996) eating is the least reported ADL or IADL with difficulty in the elderly with a prevalence of difficulty ranging from $1.3 \%$ in ages 65 to 74 years to $4.1 \%$ in ages 85 years and older.

Among all age groups, the most frequently reported difficulties were related to mobility-related activities (getting in and out of a chair, walking and using stairs) and the percentage reporting difficulty also increased with age. In comparison with less than $20 \%$ of respondents under 75 years of age, over $44 \%$ of respondents 85 years and older reported difficulty with these activities. These findings are similar to results of elder surveys conducted by the US Bureau of Census (1996) which reported difficulty with walking ranging from $9 \%$ in ages 65 to 74 years to $35 \%$ in ages 85 years and older.

Other studies of community-dwelling elders have found that mobility status was directly related to the risk of developing disabilities in old age (Guralnik et al., 1993; Guralnik et al., 1995; Langlois et al., 1996). For example, in a study of 1122 men and women 71 years of age and older, Guralnik et al. (1995) found that maintaining mobility increased the probability of remaining 
independent throughout old age. As a result of their findings, Guralnik et al. (1995) proposed that clinicians develop intervention strategies which address the early signs of changes in mobility status, such as lower extremity limitations. They recommended that addressing mobility limitations in their early stages would help postpone the development of severe disabilities in the elderly.

The greatest increases in difficulties with ADLs and IADLs were between the three youngest age groups and the oldest group (85+ years). This suggests that individuals representing the oldest-old ( $85+$ years) are the most vulnerable to becoming dependent on others for the performance of activities of daily living.

Level of difficulty with ADLs and IADLs in the four age groups. Among respondents who reported difficulity with an ADL or IADL, the level of difficulty with all ADLs and IADLs tended to increase with age. In the three youngest age groups, the most frequently reported level of difficulty as "some" from a threepoint scale of "some", "a lot", and "unable". The oldest age group (85+ years) had the highest percentages of respondents reporting being unable to perform an ADL or IADL without assistance or special equipment. The percentage of respondents over 85 years who reported being unable to perform an ADL or IADL ranged from $9.8 \%$ (walking) to $74.3 \%$ (doing laundry). In comparison, respondents 60 to 64 years who reported being unable to perform an ADL or IADL ranged from $0.0 \%$ (eating and taking care of appearance) to $24.1 \%$ (getting to places in the community). 
As was the case for the presence of difficulties, the analyses of levels of difficulty with ADLs and IADLs also suggest that among all age groups of elderly, the oldest-old ( $85+$ years) are most likely in need of assistance for the performance of their basic activities of daily living.

\section{Number and mean number of difficulties with ADLs and IADLs in the}

four age groups. The study found that the numbers of ADLs and IADLs that respondents reported they had difficulty with also increased with age. The percentage of respondents reporting difficulty with four to eight ADLs was highest in the oldest age group (33.7\%) in comparison with other groups (18.8\%, $17.8 \%$, and $15.6 \%$ ). Similar findings were seen in difficulties with IADLs. The percentage of respondents reporting difficulties with four to eight IADLs for ages 85 years and older $(50.8 \%)$ was more than double the percentages of the other age groups $(17.1 \%, 29.9 \%, 18.7 \%)$.

Likewise, the oldest age group had significantly higher mean number of difficulties with ADLs $(\underline{M}=3.07)$ and IADLs $(\underline{M}=4.03)$ in comparison with the other age groups.

These findings support the observation that the level of functioning tends to remain relatively stable with slight declines in function during early (60-74 years) and middle (75-84 years) old age. However, during late old age (85+ years) there appear to be dramatic declines in functioning and the likelihood of having multiple disabilities substantially increases in extreme old age. This 
suggests that the need for personal assistance in the performance ADLs and IADLs is substantially higher among the oldest-old ( $85+$ years) in comparison to their younger cohorts.

The results of this study also point to the need for early intervention during the younger stages of old age (60-84 years) to address functional limitations before they reach extreme levels of severity and cause individuals to become unable to perform basic tasks of daily living independently. In an analysis of data from the Longitudinal Study on Aging of 5,000 community-dwelling elders aged 70 years and older in the US, Crimmins and Saito (1993) found that the likelihood of experiencing improvements in functional capabilities was related to the severity and number of functional limitations. The odds ratio of experiencing an improvement in function was significantly decreased in individuals who reported having limitations with several ADLs or IADLs or reported being unable to perform an activity.

Difficulties with ADLs and IADLs in the four age groups by gender. Among both males and females, the percentage of respondents reporting difficulties with most ADLs and IADLs tended to increase with age. However, for each of the activities examined, there were differences between the genders in the percentages of respondents reporting difficulty. For all activities and across all age groups, higher percentages of females reported difficulties than males. Furthermore, there were four activities (difficulties with dressing, getting in and 
out of a chair, managing money and getting to places in the community) for which males did not report significant increases in difficulty with age. These findings are consistent with national surveys which have found that elderly females were more likely to have difficulties with ADLs and IADLs (US Bureau of the Census, 1996).

The gender differences in difficulties with ADLs and IADLs seen in this study may have been affected by the small sample sizes of males reporting difficulties across the four age groups. For three ADLs (eating, taking care of appearance, and using the toilet) and one IADL (taking medicine), the numbers of males reporting difficulties were insufficient to allow statistical comparisons across age groups.

Among both males and females, the number of difficulties with ADLs and IADLs tended to increase with age. However, this increase was significant only for females, not for males. This finding supports the observation that females report higher rates of disabilities than males (Verbrugge and Jette, 1994). As stated above, the gender differences found in this study may have been affected by the small number of males across the four age groups reporting difficulties with ADLs and IADLs.

For both males and females, the mean numbers of difficulties with ADLs and IADLs were highest in the oldest age groups in comparison to the younger ones. Among females, the differences between the oldest age group and the other 
groups were significant for both ADLs and IADLs. However, among males, the mean number of difficulties with ADLs was not significantly different across age groups, but for IADLs there was a significant difference between the oldest age group ( $85+$ years) and the second youngest group (65-74 years). Again, these results may have been influenced by the smaller samples of males in the four age groups in comparison with females.

One factor that may have contributed to the higher percentage of females reporting difficulties with functional activities is that throughout old age, females tend to experience more non-fatal chronic and disabling health problems than males (Verbrugge and Jette, 1994). The risk of developing multiple chronic conditions is also higher for females than males (Verbrugge and Jette, 1994). Furthermore, elderly females are more likely to live alone than elderly males (U.S. Bureau of the Census, 1996). It is likely that the level of difficulty experienced by an elderly man who lives with his spouse and receives routine assistance to perform the basic activities of daily living may not be as obvious as the level of difficulty experienced by an elderly woman who is widowed and lives alone. For example, an elderly married man may receive help daily from his wife to put on his shoes and socks. The assistance the man receives from his wife is so habitual that he does not even realizes he has difficulty performing the task. Therefore, when asked in a survey the man may not report having difficulty with the task of dressing. In contrast, an elderly woman who lives alone and has 
difficulty dressing herself will likely rely on assistive devices or personal assistance to perform the task. In this scenario it is probably apparent that the woman is unable to dress independently, and the woman would likely report having difficulty with the task.

Research questions three and four: Is there a relationship between self-reported health and self-reported functional ability of the elderly? Does the relationship between self-reported health and self-reported functional ability differ among four age groups of elderly individuals?

The study found a relationship between self-reported health and selfreported functional ability of the elderly. In all four age groups, as the number of difficulties with ADLs or IADLs increased, self-reported health became poorer.

The study also found that the relationship between self-reported health and self-reported functional ability differed among the four age groups. In comparing the oldest age group to the three other groups, the relationship tended to weaken with age. These findings suggest that the influence of functional status on selfassessments of health may change as a person ages. Difficulties with ADLs and IADLs appear to play a less significant role in determining how one measures health status in very old age. In this study, the correlation between self-reported health and difficulties with ADLs ranged from $\underline{r}=.463$ in ages 60 to 64 years to $\underline{r}=.310$ in ages 85 years and older. Similarly, the correlations between selfreported health and difficulties with IADLs were higher in the two younger age 
groups ( $\underline{r}=.326$ and $\underline{r}=.420)$ in comparison with the two older ones $(\underline{r}=.249$ and $\underline{r}=.215)$.

In all age groups, as the number of difficulties with ADLs and IADLs increased, self-reported health tended to be poorer. However, this relationship weakened with age. In comparison with the younger age groups, the relationship between self-reported health and difficulties with ADLs and IADLs in the older groups were weaker. These findings suggest that with increasing age, difficulties with functional abilities may play a less significant role in determining selfreported health status. These findings are consistent with observations made by Borawski et al. (1996) from a qualitative study of health appraisals of the elderly. Borawski et al. (1996) found that older respondents tended to focus on attitudinal or behavioral factors rather than physical functioning to assess health status. For example, having an optimistic outlook on life and practicing health promoting behaviors, such as regular exercise, were associated with positive assessments of health.

In a study that examined self-reported health, functional ability and mortality in the elderly, Chipperfield (1993) found that health optimists (subjects who reported more positive levels of health than objective functional status) were at a lower risk of mortality than health pessimists (subjects who reported more negative levels of health than objective functional status). 
Likewise, in a longitudinal study of 147 individuals aged 84 to 90 years from Sweden, Femia et al. (1997) found that subjects who continued to report favorable self-assessments of health in spite of increasing physical frailty were less likely to experience functional decline than those who reported poorer health over time. They suggested that in the oldest-old ( $85+$ years), psychological factors (such as subjective health) may serve to counteract the negative influences of increased physical limitations.

These studies help to explain the findings of the present study. The greatest differences in the relationship between self-reported health and functional ability across age groups were found between the oldest group ( $85+$ years) and the other groups. This relationship was weakest in the oldest age group in comparison with the other age groups. This suggests that functional limitations play a less prominent role in measuring self-reported health in the oldest-old ( $85+$ years) in comparison to younger groups of elderly. Research by Menec and Chipperfield (1997) supports this idea that health perceptions play an important role in the elderly, especially in the oldest age groups. They compared perceived health, perceived control, and functional status in two age groups of elderly, young-old (65-79 years) and old-old ( $80+$ years). They found that among the oldold but not the young-old, perceived control was significantly related to perceived health. Specifically, in old-old ( $80+$ years) subjects with functional impairments, high levels of perceived control were directly correlated with high levels of 
perceived health. This relationship was not seen in young-old (65-79 years) subjects with functional impairments.

Relationship between self-reported health and self-reported functional ability by gender. This study also found that the relationship between selfreported health and self-reported functional abilities may be influenced by the gender of the individual. Among both genders, there were significant and positive relationships between self-reported health and functional abilities in most age groups. However, the weakening of the relationship with age was significant only in females, not in males. Among males, the correlations between self-reported health and difficulties with ADLs and between self-reported health and difficulties with IADLs were not significantly different across age groups. This suggests that males and females interpret declining functional abilities in different ways. The results of the study suggests that throughout old age, males may use more objective factors (e.g., difficulties in performing functional activities) to measure health status. Whereas females may rely on more subjective factors (e.g., sense of well-being or control) to measure health. It is not surprising that there may be gender differences in the relationship between functional ability and self-reported health across age groups of elderly, especially if positive perceptions of health serve a protective function in the face of declining functional abilities. In this study as well as in others, females reported higher levels of difficulties with both ADLs and IADLs than males. Elderly females with many functional limitations 
may gain psychological benefits from viewing their health positively if they are able to adjust to the functional limitations.

\section{Implications}

Occupational therapy has traditionally acknowledged the role perceived health status plays in the maintenance of one's health. As occupational therapists working with the elderly, it may be important to view perceptions of health in the context of the aging process. In the past, an elder's perceptions of poor health in conjunction with declines in functional abilities, may have been interpreted as accurate reflections of functional decline as well as inevitable consequences of the aging process. However, this study suggests as elders age, they rely less on functional abilities to evaluate their health status. Throughout old age, elders tend to view their health favorably. There appears to be a relationship between health and functional abilities, but this relationship weakens with age, especially in the oldest old. This suggests that an elder's self-report of poor health may not simply be a reflection of age-related decline in functional ability, but rather an indication of a change or loss of control in some other aspect of the person's life. For example, the individual may be experiencing psychological problems such as depression or anxiety which could have detrimental effects on the person's level of functioning. If the person's problem is properly addressed in a timely fashion, further decline may be delayed and the person may even experience improvements in functional status. 
On the other hand, it is important to note than an elder's report of good health may imply that that individual is successfully adapting to the many life changes (both physical and psychologist ones) associated with the aging process. The individual may also have functional limitations that need to be addressed in order to prevent any further decline.

In applications of occupational therapy with the elderly, the development of successful intervention strategies relies on an accurate understanding of the perceptions of the client. Occupational therapy stresses the importance of understanding the influences that psychological, environmental and biological factors have on individual performance and quality of life. In working with the elderly it is particularly important to understand that these factors are dynamic processes and the influence of each on a person's health and well-being may continue to change as the person ages.

Results from this study demonstrate that there may be age-related differences in the relationship between self-reported health and self-reported functional ability in the elderly. This study suggests that as elders age, they rely less on functional abilities to evaluate their health status. Difficulties with ADLs and IADLs appear to play a less significant role in determining how one measures health status in very old age.

One of the clinical implications of this study concerns the importance of properly interpreting an elderly client's self-assessments of health. Self-reports of 
health may provide valuable information on how well the person is coping with day-to-day living. But, to gain an accurate assessment of the person's functional health status, it may be necessary to ask more probing questions concerning the types of difficulties the person has or the assistance required to perform specific tasks.

This knowledge can be used in the clinical setting in working with elderly clients. If perceptions of health do change with age, they may provide valuable insight into how the person is adapting to changes in functional status. This information may be used to develop treatment plans that address adaptation to functional limitations and ameliorate, or even postpone, the prospect of future functional decline.

$\underline{\text { Recommendations }}$

Conclusions from this study suggest that the relationship between selfreported health and self-reported functional abilities changes with age in the elderly. However, changes in this relationship were most evident in the oldest age group. More studies with large samples of elders from the oldest segments of society are needed to examine this phenomena in detail. This study also found that there may be differences in gender. More studies with larger samples of males from the oldest age groups are needed to examine these possible gender differences. In addition, studies that compare cultural/ethnic groups to determine whether some of the differences between self-reported health and functional 
abilities across age groups were affected by culture are needed, especially in a culturally diverse sample such as the sample in this study.

\section{$\underline{\text { Summary }}$}

Self-reported health and self-reported functional abilities across four age groups of elders from Dade County, Florida were examined in this study. The data used in the study were taken from the Comprehensive Needs Assessment Survey of Elders 60 years and older living in Dade County in 1993/1994.

Responses from 1971 elders were divided into four age groups: (a) 60 to 64 years, (b) 65 to 74 years, (c) 75 to 74 years, and (d) 85 years and older and comparisons were made across age groups. Males and females were also examined separately across age groups.

Self-reported health was measured by the response to the question, "Compared to others your age, how would you rate your overall health?" Selfreported functional ability was examined using a pair of questions for each of sixteen activities of daily living ( 8 ADLs and 8 IADLs). The first question asked "Because of a health problem, do you have difficulty with (the specified ADL or IADL)?". The second question asked the respondent to rate the level of difficulty on a three-level scale (some difficulty, a lot of difficulty, or completely unable).

This study found age-related differences in the relationships between selfreported health and self-reported functional ability in the elderly. Across all age groups, as the number of difficulties with ADLs and IADLs increased, self- 
reported health tended to become poorer. However, this relationship weakened with age. In the oldest age group (85+ years), difficulties with ADLs and IADLs appeared to play a less significant role in determining self-reported health status.

The major findings from this study were:

(1) Self-reported health ratings were significantly different across age groups. All age groups reported relatively high frequencies of positive health, but ratings of "excellent" and "good" health decreased with age;

(2) Difficulties with self-reported functional abilities increased with age, but this increase was most dramatic in the oldest age group ( $85+$ years);

(3) There was a positive relationship between self-reported health and self-reported functional ability in the four age groups and as the number of difficulties with ADLs or IADLs increased, self-reported health became poorer;

(4) The relationship between self-reported health and self-reported functional ability weakened with age; and

(5) There were differences in the distributions of males and females in all of the comparisons of self-reported health and self-reported functional abilities across the four age groups. 


\section{REFERENCES}

Ailinger, R.L. (1989). Self-assessed health of Hispanic elderly persons. Journal of Community Health, $6,113-118$.

Baltes, P.B. and Smith, J. (1997). A systemic-wholistic view of psychological functioning in very old age: introduction to a collection of articles from the Berlin Aging Study. Psychology and Aging, 12, 395-409.

Bernard, S.L., Kincade, J.E., Konrad, T.R., Arcury, T.A., Rabiner, D.J., Woomert, A., DeFriese, G.H., \& Ory, M.G. (1997). Predicting mortality from community surveys of older adults: the importance of self-rated functional ability. Journal of Gerontology: Social Sciences, 52B, S155-S163.

Biggar, J.C. (1985). Demographic, socioeconomic, and program aspects. In G.H. Maguire (Ed.), Care of the Elderly: A Health Team Approach (pp. 3-15). Boston, MA: Little, Brown and Company.

Borawski, E.A., Kinney, J.M. \& Kahana, E. (1996). The meaning of older adults' health appraisals: congruence with health status and determinants of mortality. Journal of Gerontology: Social Sciences, 51B, S157-S170.

Bowling, A. and Grundy, E. (1997). Activities of daily living: changes in functional ability in three samples of elderly and very elderly people. Age and Ageing, 26, 107-114.

Bowling, A., Farquhar, M., Grundy, E. \& Formby, J. (1993). Changes in life satisfaction over a two and a half year period among very elderly people living in London. Social Sciences and Medicine, 36, 641-655. 
Chappell, N.L., (1994). Home care research: what does it tell us? The Gerontologist, 34, 116-120.

Chipperfield, J.G. (1993). Incongruence between health perceptions and health problems. Journal of Aging and Health, 5, 475-496.

Christensen. H., Jorm, A.F., Henderson, A.S., MacKinnon, A.J., Korten, A.E., \& Scott, J.R. (1994). The relationship between health and cognitive functioning in a sample of elderly people in the community. Age and Ageing, 23, 204-212.

Condon, K.M., Dunlop, B.D. \& Rothman, M.B. (1994). Elders in Dade County, Florida: Information from the 1990 United States census. Southeast Florida Center on Aging, Forida International University, Miami, Florida.

Cousins, S. (1997). Validity and reliability of self-reported health of persons aged 70 and older. Health Care for Women International, 18, 165-174.

Cress, M.E., Schechtman, K.B., Mulrow, C.D., Fiatarone, M.A., Gerety, M.B., \& Buchner, D.M. (1995). Relationship between physical performance and self-perceived physical function. Journal of the American Geriatrics Society, 43, 93-101.

Crimmins, E.M. and Saito, Y. (1993). Getting better and getting worse:

Transitions in functional status among older Americans. Journal of Aging and Health, 5, 3-36.

Dorevitch, M.I., Cossar, R.M., Bailey, F.J., Bisset, T., Lewis, S.J., Wise, L.A., \& MacLennan, W.J. (1992). The accuracy of self and informant ratings of physical functional capacity in the elderly. Journal of Clinical Epidemiology, 45, 791-798. 
Elam, J.T., Graney, M.J., Beaver, T., Derwi, D., Appledate, W.B., \& Miller, S.T. (1991). Comparison of subjective ratins of function with observed functional ability of frail older persons. American Journal of Public Health, 81, 1127-1130.

Femia, E.E., Zarit, S.H. \& Johansson, B. (1997). Predicting change in activities of daily living: a longitudinal study of the oldest old in Sweden. Journal of Gerontology: Psychological Sciences, 52B, P294-P302.

Fisher, A.G. (1992). Functional measures, part 2: selecting the right test, minimizing the limitations. American Journal of Occupation Therapy, 46, 278-281.

Fried, L.P., Kasper, J.D., Guralnik, J.M., \& Simonsick, E.M. (1995). The Women's Health and Aging Study: an introduction. In: Gurlanik, J.M., Fried, L.P., Simonsick, E.M., eds. The Women's Health and Aging Study. NIH Pub. No. 95-4009. Bethesda, MD: National Institute on Aging, 1995, pp 1-5.

Grand, A., Grosclaude, P., Bocquet, H., Pous, J., \& Albarede, J.L. (1988). Predictive value of life events, psychosocial factors and self-rated health on disability in an elderly rural French population. Social Sciences and Medicine, 27, 1337-1342.

Guralnik, J.M., Ferrucci, L., Simonsick, E.M., Salive, M.E., and Wallace, R.B. (1995). Lower-extremity function in persons over the age of 70 years as a predictor of subsequent disability. New England Journal of Medicine, 332, 556-561.

Guralnik, J.M., LaCroix, A.Z., Abbott, R.D., Berkman, L.F., Satterfield, B., Evans, D.A., and Wallace, R.B. (1993). Maintaining mobility in late life. American Journal of Epidemiology, 137, 845-857. 
Halpert, B.P., \& Zimmerman, M.K. (1986). The health status of the "old-old": a reconsideration. Social Science and Medicine, 22, 893-899.

Hays, J.C., Schoenfeld, D.E. \& Blazer, D.G. (1996). Determinants of poor selfrated health in late life. American Journal of Geriatric Psychiatry, 4, 188-196.

Ho, S.C., Woo, J., Yuen, Y.K., Sham, A. and Chan, S.G. (1997). Predictors of mobility decline: the Hong Kong Old-Old Study. Journal of Geronotology: Medical Sciences, 52A, M356-M362.

Hoeymans, E.J.M., Feskens, E.M.J., Kromhout, D. \& Van Den Bos, G.A.M. (1997a). Ageing and the relationship between functional status and self-rated health in elderly men. Social Sciences and Medicine, 45, 1527-1536.

Hoeymans, E.J.M., Feskens, E.M.J., Van Den Bos, G.A.M., \& Kromhout, D. (1997b). Age, time and cohort effects on functional status and self-rated health in elderly men. American Journal of Public Health, 87, 1620-1625.

Idler, E.L. (1993). Age differences in self-assessments of health: age changes, cohort differences, or survivorship? Journal of Gerontology: Social Sciences, 48, S289S300.

Idler, E.L. \& Benyamini (1997). Self-rated health and mortality: a review of twenty-seven community studies. Journal of Health and Social Behavior, 38, 21-37.

Idler, E.L. \& Kasl, S.V. (1995). Self-ratings of health: do they also predict change in functional ability? Journal of Gerontology: Social Sciences, 50B, S344-S353. 
Jacobs, J.W., Oosterveld, F.G., Deuxbouts, N., Rasker, J.J., Taal, E., Dequeker, J. \& Uytterhoeven, R. (1992). Opinions of patients with rheumatoud arthritis about their own functional capacity: how valid is it? Annals of the Rheumatic Diseases, 51, 765768.

Jagger, C., Spiers, N.A. \& Clarke, M. (1993). Factors associated with decline in function, institutionalization and mortality of elderly people. Age and Ageing, 22, 190197.

Jette, A.M. (1994). How measurement techniques influence estimates of disability in older populations. Social Sciences and Medicine, 38, 937-942.

Johnson, R.J. \& Wolinsky, F.D. (1993). The structure of health status among older adults: disease, disability, functional limitation, and perceived health. Journal of Health and Social Behavior, 34, 105-121.

Johnson, R.J. \& Wolinsky, F.D. (1994). Gender, race and health: the structure of health status among older adults. The Gerontologist, 34, 24-35.

Jylha, M., Guralnik, J.M., Ferrucci, L., Jokela, J., and Heikkinen, E. (1998). Is self-rated health comparable across cultures and gender? Journal of Gerontology: Social Sciences, 53B, S144-S152.

Kaplan, G.A., Strawbridge, W.J., Camacho, T. \& Cohen, R.D. (1993). Factors associated with change in physical functioning in the elderly. Journal of Aging and Health, 5, 140-153. 
Kielhofner, G. (1995). Development of occupation. In G. Kielhofner (Ed.), $\underline{A}$ Model of Human Occupation: Theory and Application (pp.139-154). Baltimore, Maryland: Williams and Wilkins.

Kielfhofner, G. \& Forsyth, K. (1997). The model of human occupation: an overview of current concepts. British Journal of Occupational Therapy, 60, 103-110.

Koval, M. \& Dobie, S. (1996). Why do elderly seek or avoid care? A qualitative analysis. Family Medicine, 28, 352-357.

Krause, N.M. \& Jay, G.M. (1994). What do global self-rated health items measure? Medical Care, 32, 930-942.

Langlois, J.A., Maggi, S., Harris, T., Simonsick, E.M., Ferrucci, L., Pavan, M., Sartori, L., \& Enzi, G. (1996). Self-report of difficulty in performing functional activities identifies a broad range of disability in old age. Journal of the American Geriatrics Society, 44, 1421-1428.

Lazaridis, E.N., Rudberg, M.A., Furner, S.E., \& Cassel, C.K. (1994). Do activities of daily living have a hierarchical structure? Journal of Gerontology: Medical Sciences, 49. M47-M51.

Lindgren, A.M., Svarsudd, K., \& Tibblin, G. (1994). Facters related to perceived health among elderly people: The Albertina Project. Age and Ageing, 23, 328-333.

Linn, B.S. and Linn, M.W. (1980). Objective and self-assessed health the old and very old. Social Science and Medicine, 14A, 311-315. 
Manderbacka, K. \& Lundberg, O. (1996). Examining points of reference of selfrated health among Swedish oldest-old. Archives of Gerontology and Geriatrics, 23, 4760.

Manton, K.G., Corder, L.S. \& Stallard, E. (1993). Estimates of change in chronic disablility and institutional incidence and prevalence rates in the US elderly population from the 1982, 1984, and 1989 National Long Term Care Survey. Journal of Gerontology: Social Sciences, 48, S153-S166.

Markides, K.S. \& Lee, D.J. (1990). Predictors of well-being and functioning in older Mexican Americans and Anglos. Journal of Gerontology: Social Sciences, 45, 569573.

McCallum, J., Shadbolt, B., and Wang, D. (1994). Self-rated health and survival: a 7-year follow-up study of Australian elderly. American Journal of Public Health, 84, 1100-1105.

Menec, V.H. \& Chipperfield, J.G. (1997). The interactive effect of perceived control and functional status on health and mortality among young-old and old-old adults. Journal of Gerontology: Psychological Sciences, 52B, P118-P126.

Minkler, M. \& Langhauser, C. (1988). Assessing health differences in an elderly population. A five-years follow-up. Journal of the American Geriatrics Society, 36, 113118

Mitrushina, M.N. \& Satz, P. (1991). Correlates of self-rated health in the elderly. Aging, 3, 73-77. 
Mor, V., Wilcox, V., Rakowski, W. \& Hiris, J. (1994). Functional transitions among the elderly: patterns, predictors and related hospital use. American Journal of Public Health, 84, 1274-1280.

Mossey, J.M. \& Shapiro, E. (1982). Self-rated health: a predictor of mortality among the elderly. American Journal of Public Health, 72, 800-808.

Moum, T. (1992). Self-assessed health among Norwegian adults. Social Sciences and Medicine, $35,935-947$.

Murray, J., Dunn, G., \& Tarnopolsky, A. (1982). Self-assessment of health: an exploration of the effects of physical and psychological symptoms. Psychology and Medicine, 12, 371-378.

Myers, A.M., Holliday, P.J., Harvey, K.A., \& Hutchinson, K.S. (1993).

Functional performance measures: are they superior to self-assessments? Journal of Gerontology: Medical Sciences, 48, M196-206.

Norgard, T.M. \& Rodgers, W.L. (1997). Patterns of in-home care among elderly black and white Americans. Journal of Gerontology: Series B, 52B (Special Issue), 93101.

Rakowski, W. \& Cryan, C.D. (1990). Associations among health perceptions and health status within three age groups. Journal of Aging and Health, 2, 58-80.

Reviere, R., Carter, C. \& Neuschatz, S. (1994). Longitudinal needs assessment: aging in a suburban community. Physical and Occupational Therapy in Geriatrics, 12, 115. 
Rodgers, W. \& Miller, B. (1997). A comparative analysis of ADL questions in surveys of older people. Journal of Gerontology: Series B, 52B (Special Issue), 21-36.

Rodin, J. \& McAvay, G. (1992). Determinants of change in perceived health in a longitudinal study older adults. Journal of Gerontology: Psychological Sciences, 47. P373-P384.

Schroll, M., Avlund, K., and Davidsen, M. (1997). Predictors of five-year functional ability in a longitudinal survey of men and women aged 75 to 80 . The 1914population in Glostrup, Denmark. Aging Clinical and Experimental Research, 9, 143152.

Siu, A.L., Hays, R.D., Ouslander, J.G., Osterwell, D., Valdez, R.B., \& Krynski, M., and Gross, A. (1993). Measuring function and health in the very old. Journal of Gerontology: Medical Sciences, 48, M10-M14.

Spector, W.D. \& Fleishman, J.A. (1998). Combining activities of daily living with instrumental activities of daily living to measure functional disability. Journal of Gerontology: Social Sciences, 53B, S46-S57.

Spiers, N., Jagger, C. \& Clarke, M. (1996). Physical function and perceived health: cohort differences and interrelationships in older people. Journal of Gerontology: Social Sciences, 51B, S226-S233.

Stump, T.E., Clark, D.O., Johnson, R.J. \& Wolinsky, F.D. (1997). The structure of health status among Hispanic, African American, and white older adults. Journal of Gerontology: Series B, 52B (Special Issue), 49-60. 
US Bureau of the Census (1996). Sixty-five plus in the United States. Current Population Reports, Special Studies P23-190, Washington, D.C.: US Government Printing Office.

Verbrugge, L.M. \& Jette, A.M. (1994). The disablement process. Social Sciences and Medicine, 38, 1-14.

Wiener, J.M., Hanley, R.J., Clark, R., \& Van Norstrand, J.F. (1990). Measuring the activities of daily living: comparisons across national surveys. $\underline{\text { Journal of }}$ Gerontology: Social Sciences, 45, S229-S237.

Wilcox, V., Kasl, S.V. \& Idler, E.L. (1996). Self-rated health and physical disability in elderly survivors of a major medical event. Journal of Gerontology: Social Sciences, 51B, S96-S104.

Wolinsky, F.D. \& Johnson, R.J. (1994). Perceived health status and mortality among older men and women. Journal of Gerontology: Social Sciences, 47, S304-S312.

Zarit, S.H., Johannson, B., \& Berg, S. (1993). Functional impairment and codisability in the oldest old. Journal of Aging and Health, 5, 291-305.

Zarit, S.H., Johannson, B., \& Malmberg, B. (1995). Changes in functional competency in the oldest old: a longitudinal study. Journal of Aging and Health, 7, 3-23. 